\title{
Whole-genome sequence of an evolved Clostridium pasteurianum strain reveals SpoOA deficiency responsible for increased butanol production and superior growth
}

\author{
Nicholas R. Sandoval ${ }^{1 *}$, Keerthi P. Venkataramanan' ${ }^{1}$ Theodore S. Groth ${ }^{1}$ and Eleftherios T. Papoutsakis ${ }^{1,2}$
}

\begin{abstract}
Background: Biodiesel production results in crude glycerol waste from the transesterification of fatty acids (10\% w/w). The solventogenic Clostridium pasteurianum, an anaerobic Firmicute, can produce butanol from glycerol as the sole carbon source. Coupling butanol fermentation with biodiesel production can improve the overall economic viability of biofuels. However, crude glycerol contains growth-inhibiting byproducts which reduce feedstock consumption and solvent production.

Results: To obtain a strain with improved characteristics, a random mutagenesis and directed evolution selection technique was used. A wild-type C. pasteurianum (ATCC 6013) culture was chemically mutagenized, and the resulting population underwent 10 days of selection in increasing concentrations of crude glycerol (80-150 g/L). The bestperforming mutant (M150B) showed a $91 \%$ increase in butanol production in $100 \mathrm{~g} / \mathrm{L}$ crude glycerol compared to the wild-type strain, as well as increased growth rate, a higher final optical density, and less production of the side product PDO (1,3-propanediol). Wild-type and M150B strains were sequenced via Single Molecule Real-Time (SMRT) sequencing. Mutations introduced to the M150B genome were identified by sequence comparison to the wild-type and published closed sequences. A major mutation (a deletion) in the gene of the master transcriptional regulator of sporulation, Spo0A, was identified. A spo0A single gene knockout strain was constructed using a double--crossover genome-editing method. The Spo0A-deficient strain showed similar tolerance to crude glycerol as the evolved mutant strain M150B. Methylation patterns on genomic DNA identified by SMRT sequencing were used to transform plasmid DNA to overcome the native C. pasteurianum restriction endonuclease.
\end{abstract}

Conclusions: Solvent production in the absence of Spo0A shows C. pasteurianum differs in solvent-production regulation compared to other solventogenic Clostridium. Growth-associated butanol production shows C. pasteurianum to be an attractive option for further engineering as it may prove a better candidate for butanol production through continuous fermentation.

Keywords: Butanol, Clostridium pasteurianum, Spo0A, Methylome, Mutagenesis, SMRT sequencing

\section{Background}

The production of biodiesel has led to production of large quantities of waste glycerol [1]. The transesterification

\footnotetext{
*Correspondence: sandovan@udel.edu

${ }^{1}$ Department of Chemical and Biomolecular Engineering and the Delaware Biotechnology Institute, University of Delaware, 15 Innovation Way, Newark, DE 19711, USA

Full list of author information is available at the end of the article
}

of plant- and animal-derived triglycerides with methanol yields $10 \mathrm{wt} \%$ crude glycerol. Crude glycerol can be refined, but increased production of biodiesel has flooded the market, making such processes economically unviable [2]; this economic shift has moved glycerol from coproduct to waste [3]. Conversely, the excess crude glycerol makes it an ideal feedstock for producing chemicals and biofuels. Crude glycerol has been utilized in various 
ways including as a supplement of livestock diets, as a reactant for chemical catalytic processes, and as a feedstock for chemicals produced by bioconversion [4].

Clostridium pasteurianum (Cpa), a $\mathrm{Gram}^{+}$Firmicute obligate anaerobe, is capable of making $n$-butanol and 1,3-propanediol (PDO) directly from glycerol as sole carbon source, a capability not shared by other wellstudied Clostridium organisms [5-7]. Butanol is of particular interest as it is fungible with gasoline due to its high energy density, low vapor pressure, and low water solubility $(77 \mathrm{~g} / \mathrm{L})$. As glycerol is a more reduced carbon source than glucose, the theoretical yield for butanol production from glycerol is $17 \%$ higher than from glucose on a carbon-mole basis. This reducing power is released in the initial step of glycerol degradation in the form of NADH. Cpa has been shown to produce up to $17 \mathrm{~g} / \mathrm{L}$ of butanol in optimized batch culture [8]. In a more recent study, a mutant Cpa strain was shown to produce up to $17.8 \mathrm{~g} / \mathrm{L}$ butanol from pure glycerol at very high rates from high-density cultures, with minimal byproduct formation [9].

The impurities of crude glycerol are inhibitory to microbial growth $[1,2,10-12]$, and are thus a large obstacle to using crude glycerol for producing fuels and chemicals. Fatty acids, salts, and alcohol from biodiesel production persist in significant amounts in crude glycerol. Growth on $25 \mathrm{~g} / \mathrm{L}$ crude glycerol has been shown to lead to a $40 \%$ decrease in solvent production [2]. In addition, increased lag times and decreased substrate uptake have been reported for several Clostridium organisms when grown on crude glycerol $[2,13]$. The most toxic of these impurities is linoleic acid, a polyunsaturated omega- 6 fatty acid [12]. The nonlinear structure caused by the two double bonds likely causes membrane depolarization [14]. Cpa solvent production has been shown to be completely abolished at $1.25 \mathrm{~g} / \mathrm{L}$ linoleic acid (along with severely inhibited growth), whereas production of solvents was not greatly affected by fatty acids with lower levels of saturation [12]. In order for crude glycerol to be effectively converted to butanol, a tolerant strain of $\mathrm{Cpa}$ must be developed.

The Cpa genome has recently been sequenced and shown to be amenable to genome editing [11, 15], but low transformation efficiencies prohibit the use of high throughput library-based genome engineering tools. Here, we employed directed evolution of mutagentreated Cpa aiming to select mutants tolerant to and using increasing concentrations of crude glycerol as the primary carbon and energy source. A tolerant mutant was isolated which exhibited increased tolerance to crude glycerol and improved butanol productivity. Single Molecule Real-Time (SMRT) sequencing of the mutant and WT strains identified all mutations in the tolerant mutant. Among other variants, a 24-bp deletion was identified in the key sporulation transcriptional regulator Spo0A. We confirm the that Spo0A inactivation is responsible for the tolerant and improved solvent-producing phenotype; we knocked out the spoOA gene in the WT strain and show that the engineered strain displays similar tolerance to crude glycerol as the evolved strain. In order to interpret the impact of Spo0A knockout on product formation, we used the Cpa genome sequencing to identify and map key product-formation genes, and analyzed them in a comparative analysis against other solventogenic Clostridium organisms. SMRT analysis enabled the identification of multiple DNA methylation motifs, some novel, including the confirmation of a cytosine methylation motif which enables the evasion of the endogenous type II endonuclease. We used a codonoptimized version of the native DNA methylase to enable efficient plasmid DNA transformation.

\section{Results}

\section{Mutation, selection, and isolation of a mutant strain} tolerant to crude glycerol

Industrial butanol production from crude glycerol would require a strain that can readily grow on crude glycerol with a high growth rate and short lag phase and that can produce high butanol titers with good selectivity. The negative effect of crude glycerol on the growth of the WT strain is apparent at $80 \mathrm{~g} / \mathrm{L}$ (Fig. 1a), while no growth was observed at $150 \mathrm{~g} / \mathrm{L}$ or higher. It has been shown that the most toxic components of crude glycerol are the residual fatty acids that persist in the glycerol layer in biodiesel production [12]. The most toxic of these was found to be those with higher degrees of unsaturation, and notably, linoleic acid, which completely abolishes growth of Cpa at $1.25 \mathrm{~g} / \mathrm{L}$ [12] and has been found to negatively affect growth rates of some $\mathrm{Gram}^{+}$bacteria at concentrations as low as $3 \mathrm{mg} / \mathrm{L}$ [16]. Here, we found growth of Cpa was almost completely abolished at concentrations of $0.075 \mathrm{~g} / \mathrm{L}$ when grown on $30 \mathrm{~g} / \mathrm{L}$ glycerol and significantly affected at just $0.02 \mathrm{~g} / \mathrm{L}$ 9-cis,12-cis-linoleic acid (Fig. 1b).

The crude glycerol (Feed Energy, Des Moines, Iowa) used in this study was analyzed for its respective components (by New Jersey Feed Lab). $0.8-2 \%$ of the crude glycerol is fatty acids. The variation in concentration of fatty acids in the crude glycerol depends on the depth of the sample (low at the bottom, high at the top). As we attempted to uniformly sample from the top of the glycerol for each study, variations are to be expected from batch to batch and especially over time as the crude glycerol stock was depleted. The fatty acid profile of the crude glycerol was over half attributed to linoleic acid (Fig. 1c).

In order to obtain a strain of $\mathrm{Cpa}$ that is tolerant to crude glycerol, a mutagenesis and directed evolution 


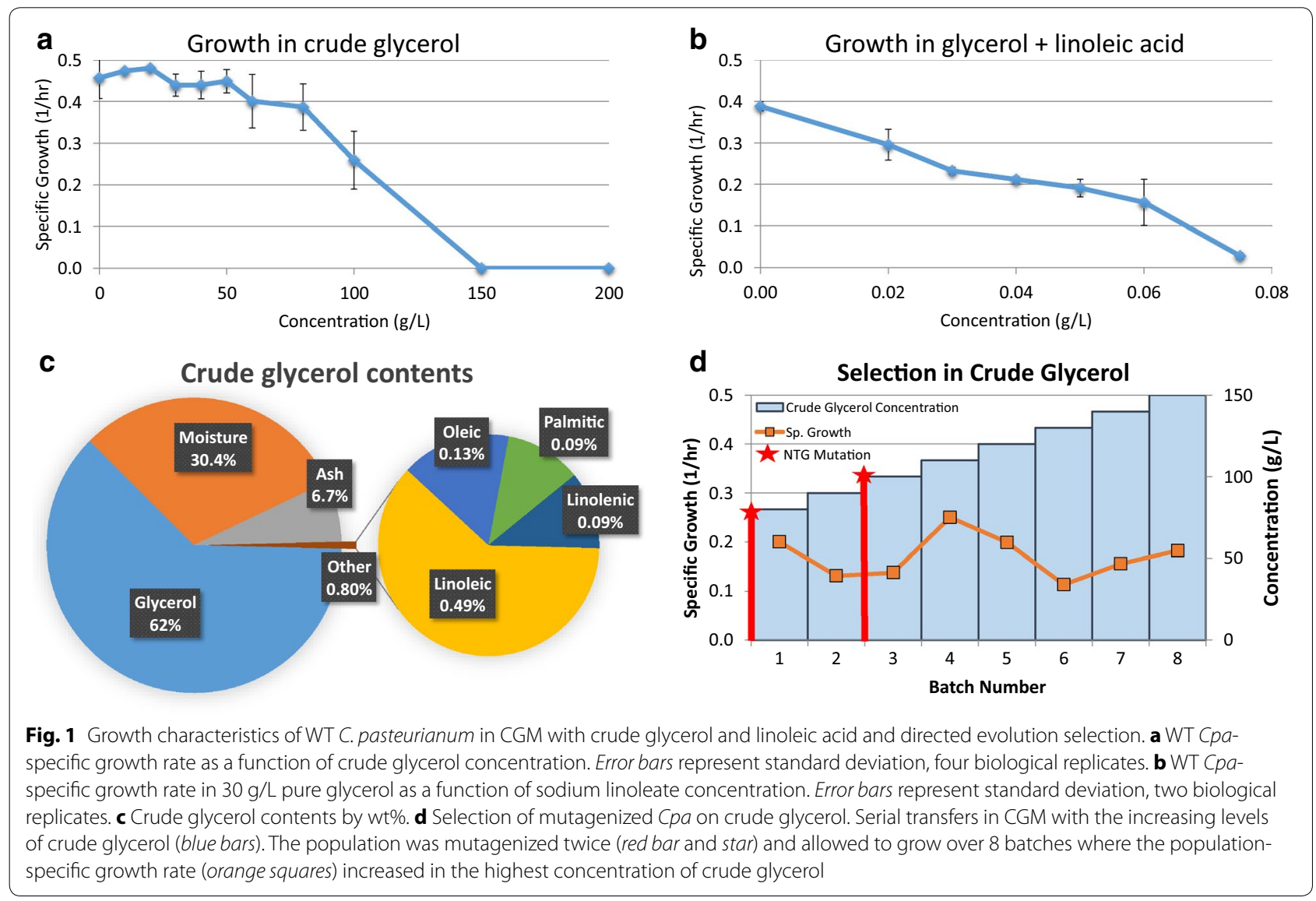

strategy was employed. Cpa cultures were mutated twice by exposure to $50 \mu \mathrm{g} / \mathrm{mL} N$-methyl- $N^{\prime}$-nitro$\mathrm{N}$-nitrosoguanidine (NTG) for $15 \mathrm{~min}$, washed thrice with PT buffer, and recovered in 2xYTG media as described [17]. The mutated Cpa population was grown on CGM-crude glycerol medium and serially transferred eight times in increasing concentrations of crude glycerol (Fig. 1d). Each batch increased in crude glycerol by $10 \mathrm{~g} / \mathrm{L}$ starting with $80 \mathrm{~g} / \mathrm{L}$ in batch 1 . After 10 days and 28 generations of growth, the final population sustained strong growth with little lag time in $150 \mathrm{~g} / \mathrm{L}$ crude glycerol, a level that completely inhibited growth of the WT strain. Single colonies from the final population were isolated from solid media and assayed for growth in $100 \mathrm{~g} / \mathrm{L}$ crude glycerol. A single mutant (M150B) was identified with consistently short lag-phase times.

In simple batch cultures without $\mathrm{pH}$ control and feeding or medium optimization, Cpa strain M150B showed a decreased lag phase, $65 \%$ higher glycerol consumption $(40.4 \mathrm{~g} / \mathrm{L})$, and $91 \%$ higher butanol production (final titer $7.1 \mathrm{~g} / \mathrm{L}$ ) compared to the WT in $100 \mathrm{~g} / \mathrm{L}$ crude glycerol (Fig. 2a). The WT strain produced more PDO than the mutant (2.6 vs. $1.5 \mathrm{~g} / \mathrm{L}$ ). Interestingly, M150B also outperformed the WT strain when grown on pure glycerol (Fig. 2). While there was no lag phase for either the mutant or WT when grown on $60 \mathrm{~g} / \mathrm{L}$ pure glycerol, M150B consumed $75 \%$ more glycerol (43 g/L) and produced $80 \%$ more butanol $(11.7 \mathrm{~g} / \mathrm{L})$. As under the crude glycerol condition, the WT produced more PDO than the mutant from pure glycerol, but for both strains, less was produced overall $(1.5$ and $0.9 \mathrm{~g} / \mathrm{L})$. Acetate, a component of CGM media $(\sim 1.8 \mathrm{~g} / \mathrm{L})$, was partially consumed by both strains under both conditions. Ethanol and lactate were produced at low levels $(<0.5 \mathrm{~g} / \mathrm{L})$ in both strains under both conditions.

In addition to the improved fermentation properties, we also observed that this mutant was asporogenous. We confirmed that the M150B strain did not form spores by phase-contrast microscopy after 6 days of growth in CGM media (Additional file 1: Figure S1). We observe plentiful phase-bright sporulation in the WT cells, while the M150B cells show no such spore formation. We also performed a chloroform-based sporulation assay [18] where the WT strain survived $10 \mathrm{~min}$ of $50 \% \mathrm{v} / \mathrm{v}$ chloroform treatment, while M150B did not. 


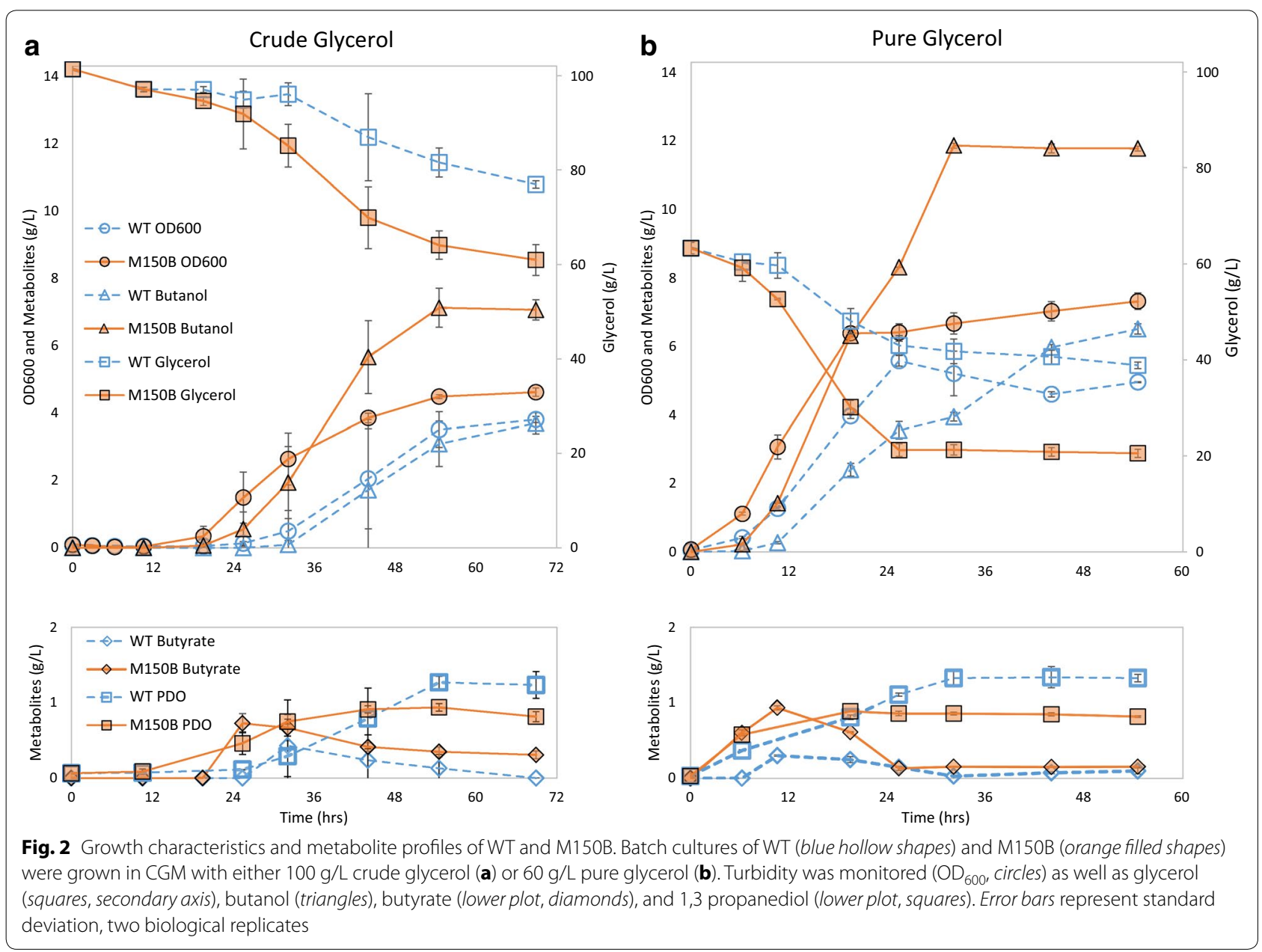

SMRT sequencing of Cpa ATCC 6013 and the M150B mutant strains identifies a large deletion on the spo0A gene as likely responsible for the tolerant and butanol-production phenotype

We desired to determine the genetic source of the improved characteristics of the evolved strain M150B. Three Cpa ATCC 6013 sequences have been published recently. Each successive genomic sequencing project has resolved the size of the genome and the number of contigs (from 4,285,687 bases assembled into 37 contigs [19], to $4,420,124 \mathrm{bp}$ in 12 contigs [15], to finally $4,351,223 \mathrm{bp}$ in a single closed circular chromosome [20]). All sequence comparisons, gene names, and genomic loci here are based on the closed circular chromosome (Genbank CP009267.1).

We sequenced both the WT and mutated strains using the Pacific Biosciences RSII. The WT genomic DNA was isolated during the transition phase, while the mutant M150B's gDNA was isolated during mid-exponential phase. The WT sequencing resulted in 46,455 mapped reads with an average length of $8271 \mathrm{bp}$ and an average
$78.4 \times$ coverage. The M150B sequencing resulted in 107,963 mapped reads with average read length of 6471 and average $121.1 \times$ coverage. The coverage of the M150B genome depended on genome locus, while that of the WT did not (Additional file 1: Supplemental Results, Figure S2); the coverage for M150B was the greatest near the origin of replication. We suspect this is due to the state of growth of the culture at the time of gDNA harvesting.

We compared our sequence of the WT ATCC 6013 strain with the most recently published sequence [20] and observed 17 differences (Additional file 1: Table S1). We did not observe the mutation noted in the Spo0A gene by Rotta et al. [20]. In contrast to the reported sequence, position 255 of Spo0A is glutamic acid, not the lysine (or glutamine) reported for ATCC 6013, making it similar to the Cpa DSM 525 [21] sequence and other Clostridium strains. When comparing the sequence of M150B with the same published sequence, we found the same 17 differences contained in our WT strain along with 67 other variants (Table 1). Of these 67 variants, 66 were substitutions. Ten were in regions that were not annotated to 
Table 1 Sequence variants from sequenced wild-type Cpa 6013 vs. M150B

\begin{tabular}{|c|c|c|c|c|c|}
\hline Mut. locus [20] & Mut. type & CDS & Mut. & Ref. & Var. \\
\hline 135360 & Sub. & No CDS & & A & G \\
\hline 177873 & Sub. & Hypothetical cell wall-binding protein, c01710 & A267V & C & $\mathrm{T}$ \\
\hline 256066 & Sub. & Glycosyltransferase, c02430 & $1257 \mathrm{~T}$ & A & G \\
\hline 328268 & Sub. & Xanthine dehydrogenase, molybdenum binding; pudD1 & P483L & C & $\mathrm{T}$ \\
\hline 511135 & Sub. & $\begin{array}{l}\text { Pyridine nucleotide-disulfide oxidoreductase; NADH dehydroge- } \\
\text { nase; coenzyme A disulfide reductase; } 04890\end{array}$ & P187S & $\mathrm{T}$ & C \\
\hline 547010 & Sub. & Pyruvate-flavodoxin oxidoreductase; nifJ1 & S579N+ & G & A \\
\hline 609918 & Sub. & Lactose permease; lacS & P429S & G & A \\
\hline 623217 & Sub. & lysin; c05770 & A129T & G & A \\
\hline 633860 & Sub. & Hypothetical protein; c05850 & Silent & C & $\mathrm{T}$ \\
\hline 662676 & Sub. & High-affinity nickel-transport protein; nixA1 & Silent & C & $\mathrm{T}$ \\
\hline 664502 & Sub. & Methyl-accepting chemotaxis protein; c06130 & T311A & A & G \\
\hline 774540 & Sub. & Metallophosphoesterase; $\mathrm{C07050}$ & G294E & G & A \\
\hline 805746 & Sub. & Putative amidase domain-containing protein; $\mathbf{C 0 7 3 2 0}$ & G378E & G & A \\
\hline 822080 & Sub. & tRN Glu)-specific nuclease WapA; wapA1 & S1026F & C & $\mathrm{T}$ \\
\hline 849186 & Sub. & Putative glycosyltransferase; 07760 & Q641tag & G & A \\
\hline 888969 & Sub. & Phage infection protein; 08050 & $\mathrm{E} 95 \mathrm{~K}+$ & C & $\mathrm{T}$ \\
\hline 905016 & Sub. & putative L-ascorbate-6-phosphate lactonase UlaG; ulaG & $\mathrm{A} 128 \mathrm{~V}$ & C & $\mathrm{T}$ \\
\hline 959280 & Sub. & No CDS & & C & $\mathrm{T}$ \\
\hline 1010600 & Sub. & Radical SAM domain protein; 09370 & G32D & C & $\mathrm{T}$ \\
\hline 1018923 & Sub. & No CDS & & G & A \\
\hline 1034853 & Sub. & Putative AAA-ATPase; c09620 & E311K+ & G & A \\
\hline 1047038 & Sub. & DNA-binding response regulator; 099780 & Silent & G & A \\
\hline 1052341 & Sub. & Hypothetical protein; c09830 & E98K+ & G & A \\
\hline 1058795 & Sub. & Nicotinamidase; c09830 & V311+ & G & A \\
\hline 1263298 & Sub. & No CDS & & G & A \\
\hline 1384612 & Sub. & Spore germination protein $\mathrm{KA}$; gerKA2 & G15D & G & A \\
\hline 1408727 & Sub. & hypothetical protein; C13080 & $\mathrm{L} 71 \mathrm{~N}$ & G & A \\
\hline 1595471 & Sub. & Lactate-responsive regulator LIdR; C14940 & A154T & G & A \\
\hline 1597713 & Sub. & Electron transfer flavoprotein, alpha subunit; etfA1 & A300T & G & A \\
\hline 1608597 & Sub. & CAAX amino terminal protease family protein; $\mathrm{C} 15040$ & Silent & $\mathrm{T}$ & C \\
\hline 1729728 & Sub. & Integral membrane protein; 16180 & V8I+ & G & A \\
\hline 1796914 & Sub. & Phenylalanyl-tRNA synthetase beta chain; pheT & A674V & C & $\mathrm{T}$ \\
\hline 1957368 & Sub. & Flagellum-specific ATP synthase Flil; flil & $\mathrm{E} 44 \mathrm{~K}+$ & G & A \\
\hline 1973896 & Sub. & RNA polymerase sigma factor for flagellar operon; whiG & A75T & G & A \\
\hline 1976216 & Sub. & Flagellar basal-body rod protein; $f l g G 3$ & Silent & $\mathrm{T}$ & C \\
\hline 2055679 & Del. & Stage 0 sporulation protein $A ;$ spoOA & Del. 235-242 & ATACCATAAATAAATTATTTGGAT & \\
\hline 2822361 & Sub. & CRISPR-associated helicase/endonuclease Cas3; cas3 & E316F & C & $\mathrm{T}$ \\
\hline 3198907 & Sub. & No CDS & & C & $\mathrm{T}$ \\
\hline 3208358 & Sub. & Exonuclease $\mathrm{SbcC} ;$ sbcC & A558T & C & $\mathrm{T}$ \\
\hline 3222314 & Sub. & Hypothetical protein, CF-17 family; c29890 & E213K+ & C & $\mathrm{T}$ \\
\hline 3270753 & Sub. & No CDS & & C & $\mathrm{T}$ \\
\hline 3272757 & Sub. & tRNA-dihydrouridine synthase; $c 30410$ & D126K+ & C & $\mathrm{T}$ \\
\hline 3273913 & Sub. & Fe-S oxidoreductase; c30430 & T87A & A & G \\
\hline 3297381 & Sub. & No CDS & & G & A \\
\hline 3348577 & Sub. & Transcriptional regulator, TetR family; c31160 & $\mathrm{S} 20 \mathrm{~N}+$ & C & $\mathrm{T}$ \\
\hline 3399757 & Sub. & Hydrolase (HAD superfamily); c31590 & P219S & G & A \\
\hline 3439637 & Sub. & $\begin{array}{l}\text { Multiple sugar transporter, membrane-spanning permease protein } \\
\text { MsmG; msmG2 }\end{array}$ & A236V & G & A \\
\hline 3488562 & Sub. & Potassium-transporting ATPase $C$ chain; $k d p C$ & T2831 & G & A \\
\hline
\end{tabular}


Table 1 continued

\begin{tabular}{|c|c|c|c|c|c|}
\hline Mut. locus [20] & Mut. type & CDS & Mut. & Ref. & Var. \\
\hline 3497476 & Sub. & Fatty-acid peroxygenase; cypC & P255S & G & A \\
\hline 3521979 & Sub. & ATP phosphoribosyltransferase regulatory subunit; hisZ & P96L & G & A \\
\hline 3531067 & Sub. & Cysteine desulfurase; $c 32790$ & Silent & G & A \\
\hline 3535341 & Sub. & Chaperone protein HtpG; $h t p G$ & Silent & G & A \\
\hline 3593919 & Sub. & No CDS & & G & A \\
\hline 3595710 & Sub. & 2-iminoacetate synthase; thiH2 & P77S & G & A \\
\hline 3641811 & Sub. & Possible surface protein; $c 33730$ & T7421 & G & A \\
\hline 3666696 & Sub. & No CDS & & G & A \\
\hline 3698846 & Sub. & L-arabinose transport system permease; araQ2 & T2351 & G & A \\
\hline 3759007 & Sub. & hypothetical protein; c34910 & E729K+ & C & $\mathrm{T}$ \\
\hline 3776313 & Sub. & RNA-binding protein; $c 35120$ & $\mathrm{~S} 523 \mathrm{~N}+$ & C & $\mathrm{T}$ \\
\hline 3863797 & Sub. & DNA-3-methyladenine glycosylase II; c35950 & E119K+ & C & T \\
\hline 3872706 & Sub. & Autoinducer 2 sensor kinase/phosphatase LuXQ; luxQ3 & $\mathrm{E} 242 \mathrm{~F}$ & C & T \\
\hline 3909641 & Sub. & Signal-transduction and transcriptional-control protein; stc3 & $\mathrm{A} 657 \mathrm{~V}+$ & C & T \\
\hline 3935380 & Sub. & 50 S ribosomal protein $L 2 ; r p / B$ & Silent & C & $\mathrm{T}$ \\
\hline 3936650 & Sub. & 50 S ribosomal protein $\mathrm{L} 3$; rp/C & G191D & C & T \\
\hline 4163498 & Sub. & Signal transduction histidine kinase; c39070 & S439N & C & T \\
\hline 4231311 & Sub. & Putative competence-damage inducible protein; $\operatorname{cin} A$ & Silent & C & T \\
\hline
\end{tabular}

Positive substitutions are indicated by a plus symbol

contain genes. Of the 56 remaining, 14 were silent mutations, 14 were conservative amino acid substitutions, one generated a premature stop codon in a putative glycosyltransferase, and 27 others were nonconservative amino acid substitutions. In addition, we found a single deletion of $24 \mathrm{bp}$ in the gene encoding the master sporulation factor Spo0A [22] (Fig. 3).

We also observed three point mutations in flagellarelated genes. A silent mutation was found in flgG3, coding for a flagellar protein and a conservative mutation was found in the flagellum-specific ATP synthase, fli (E44K). A nonconservative mutation was found in whiG, coding for a sigma factor specific to a flagellar operon (Table 1). The A75T mutation in the WhiG gene is in a highly conserved region in WhiG and $\sigma^{\mathrm{D}}$ proteins supposed to be the promoter recognition element [23]. The combined effects of these mutations may be responsible for M150B not staying in suspension as long as its parent strain. M150B cultures consistently settle quickly and more compactly compared to the WT when not actively agitated (Additional file 1: Figure S3).

We also observed point mutations in genes related to central metabolism and solvent production. nifJ1 encoding pyruvate-flavodoxin oxidoreductase, which catalyzes pyruvate and coenzyme A to acetyl-CoA and carbon dioxide (Fig. 4) has a S579 N mutation. However, Cpa contains two paralogs, nifJ2 and nifJ3, which may compensate for the mutated nifJ1. The etfA1 gene, encoding the electron-transfer flavoprotein alpha subunit, which contains an FAD-binding domain, has an A300T mutation. The Cpa genome encodes the paralog etfA3, which contains the major domains of the EtfA (Fig. 5c). EtfA together with EtfB and butyryl-CoA dehydrogenase likely form the Etf/Bcd complex, which couples the NADHdependent reduction of crotonyl-CoA to butanoyl-CoA with the reduction of ferredoxin [24] (Fig. 4).

The deletion of $24 \mathrm{bp}$ in M150B's single copy of the spoOA gene led to an in frame deletion of eight amino acid residues in the $\sigma^{\mathrm{A}}$ activator region (Fig. 3) [25]. The $\sigma^{\mathrm{A}}$ activator region is essential for binding to $\sigma^{\mathrm{A}}$ dependent promoters [25]. This mutation is unique in that it is a deletion and not an A-G or T-C single nucleotide variant, commonly observed in NTG-mutated strains. We observed that the deletion of the 24 bp corresponded exactly with two identical 8 bp sequences (5'-ATACCATA-3') surrounding the deletion (Fig. 3). This is likely due to homologous recombination of these overlapping regions, which removed the section between these sequences and one of the copies of the sequence. It is noteworthy that while sporulation was disrupted as could be predicted by such a deletion, solvent production remained. This is unexpected as it stands in contrast to what was observed in Spo0A mutants in C. beijerinckii (Cbe) [26] and C. acetobutylicum (Cac) [22]. In those strains, Spo0A regulates the expression of key solvent genes and notably of the genes in the sol locus [22], and as a result, in their Spo0A mutants, solvent production is nearly abolished. 


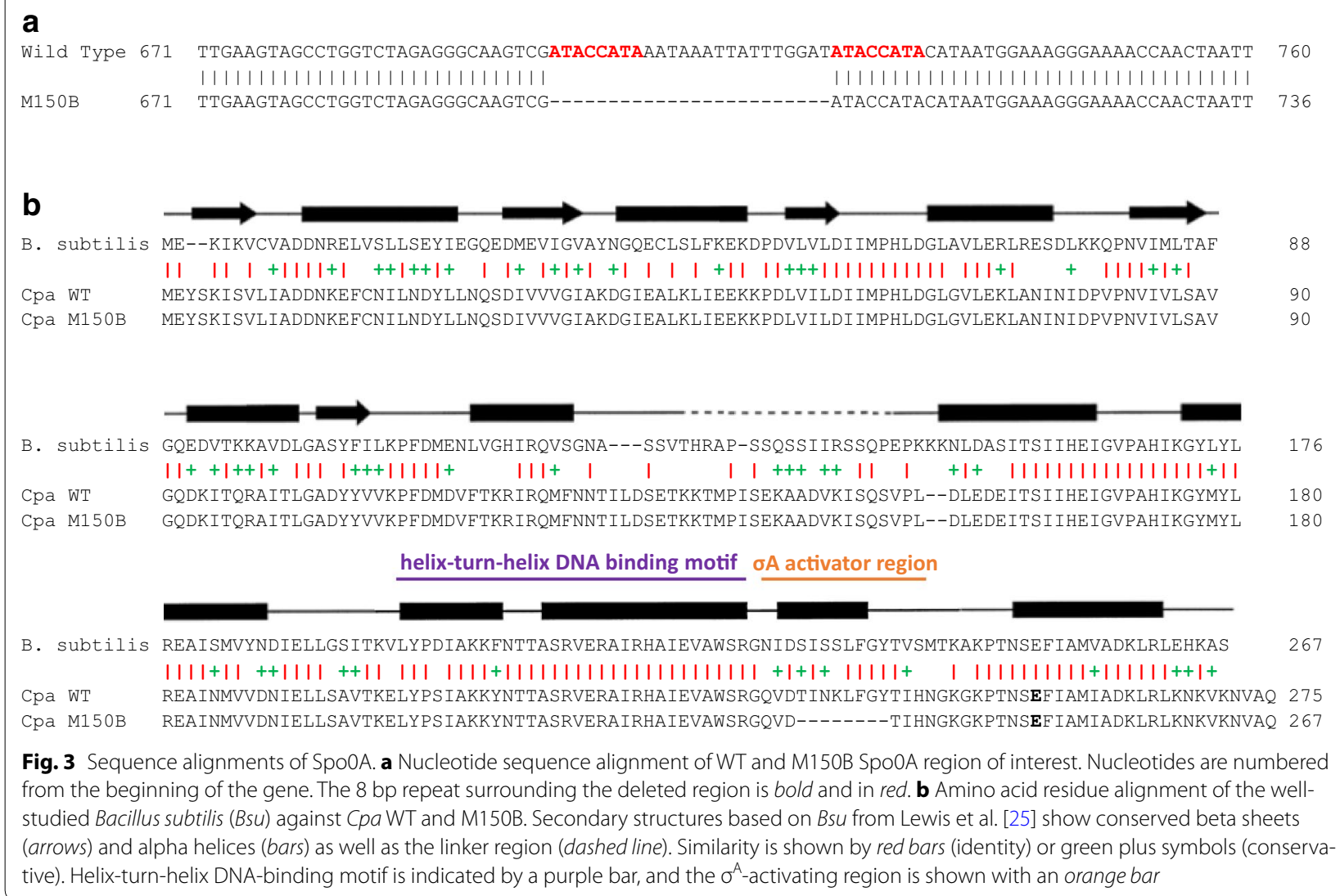

Fig. 3 Sequence alignments of SpoOA. a Nucleotide sequence alignment of WT and M150B Spo0A region of interest. Nucleotides are numbered from the beginning of the gene. The $8 \mathrm{bp}$ repeat surrounding the deleted region is bold and in red. $\mathbf{b}$ Amino acid residue alignment of the wellstudied Bacillus subtilis (Bsu) against CpaWT and M150B. Secondary structures based on Bsu from Lewis et al. [25] show conserved beta sheets (arrows) and alpha helices (bars) as well as the linker region (dashed line). Similarity is shown by red bars (identity) or green plus symbols (conservative). Helix-turn-helix DNA-binding motif is indicated by a purple bar, and the $\sigma^{A}$-activating region is shown with an orange bar

\section{Mapping the solvent-formation capabilities of $C$. pasteurianum on its sequenced genome illuminates the role of multiple gene orthologs/paralogs on its unique metabolic traits}

In order to gain a better understanding of the aforementioned differences in the regulation of solvent formation between CPa and the two well-established model solventogenic Clostridium organisms, we mapped the core primary metabolic reactions of Cpa to the sequenced genome and compared this mapping to that in Cac. This has only recently been enabled through a closed and annotated genome sequence.

Glycerol utilization by the cells leads to either entry to glycolysis at dihydroxyacetone phosphate or reduction to form 1,3-propanediol (PDO) (Fig. 4). The genes responsible for glycerol oxidation pathway into glycolysis, glycerol dehydrogenase and dihydroxyacetone kinase (dhaD1, c12150 and dhaK, c12160), are sequentially located in a likely operon with the glycerol uptake gene $g l p F$ (c12170) (Fig. 5a). It should be noted, though, that three additional glycerol dehydrogenase paralogs are located throughout the genome ( $\operatorname{lld} A 1, \mathrm{c} 28060,29 \%$ identical to $d h a D 1$ by protein; gldA2, c33610, $27 \%$; and dhaD2, c38340, $43 \%$ ). The genes for the reductive pathway to PDO are also colocated in a likely operon (Fig. 5b). The propanediol dehydratase is encoded by three genes ( $p d u E, c 22790$; $p d u D, c 22800$; and $d h a B, \mathrm{c} 22810$ ), which precede a diol dehydratase-reactivating factor gene (ddrA, c22780) and the PDO dehydrogenase (dhaT2, c22740). The PDO dehydrogenase also has an extra copy (dhaT1, c11040, $43 \%$ identical by protein). The presence of these multiple gene paralogs suggests their likely importance in achieving the fast rates of glycerol utilization and growth on glycerol.

It has been well established that Cpa ferments glycerol to form PDO and butanol (Fig. 2). Unlike the model solventogenic Clostridium Cac, it does not produce acetone $[19,27]$. It does, however, have a Cac-like sol locus on its chromosome containing adhE2 (a fusion protein coding for an aldehyde-alcohol dehydrogenase, c15160), followed by $c t f A$ and $c t f B 2$ (c15170, c15180, encoding the two units of the CoA-transferase, CoAT), and, next, in an opposite orientation a monocistronic putative $a d c$ (acetoacetate decarboxylase, Adc, c15190) (Figs. 6a, 7). In Cac, AdhE1 catalyzes the conversion of butyryl-CoA to butanol [28, 29], CoA-transferase (CoAT) catalyzes the conversion of acetoacetate to acetoacetyl-CoA [30], which is accompanied by acetate and/or butyrate uptake. 
Sandoval et al. Biotechnol Biofuels (2015) 8:227

Page 8 of 18

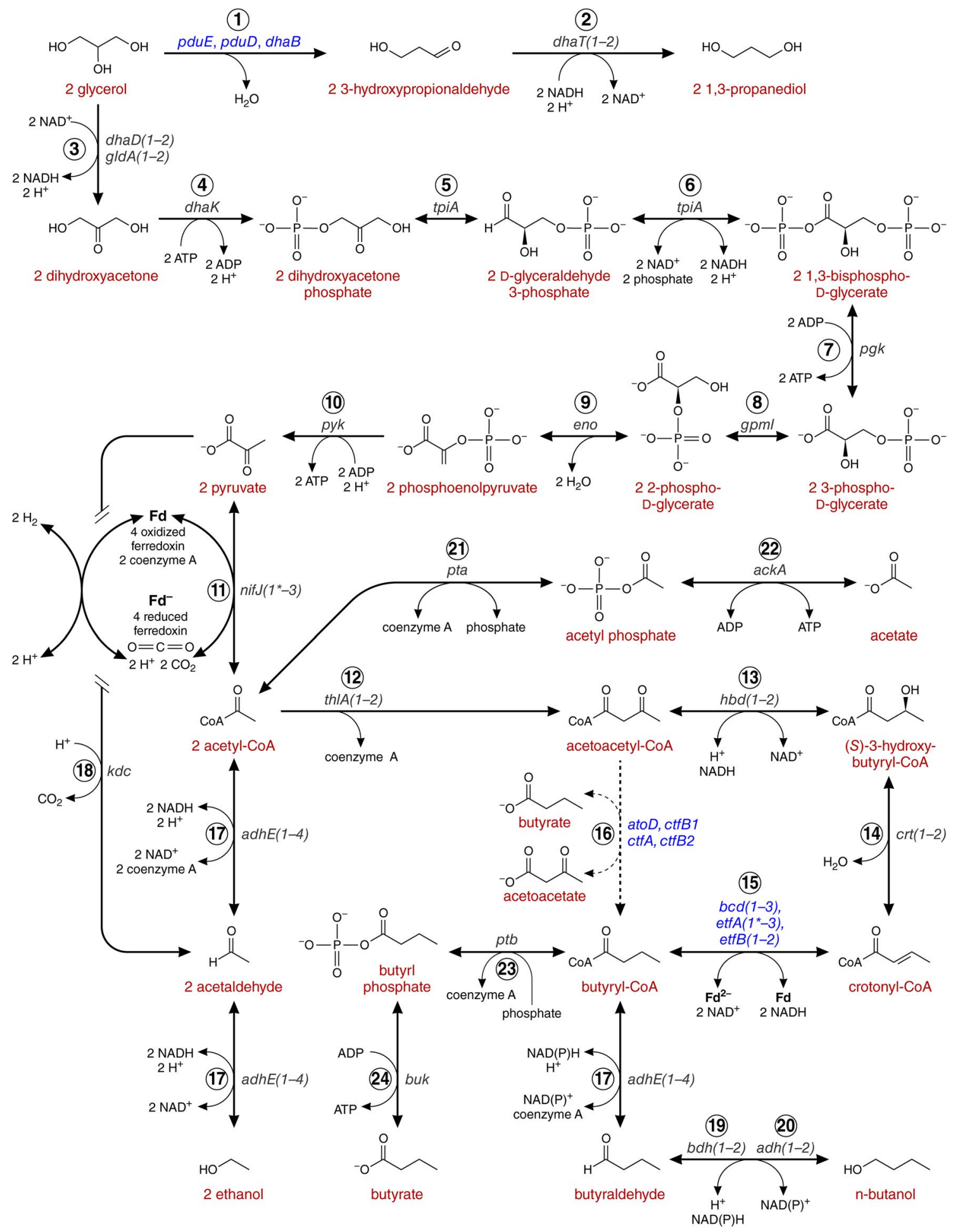


(See figure on previous page.)

Fig. 4 Genetic basis of solventogenesis from glycerol in C. pasteurianum. Possible metabolic pathways for glycerol to 1,3 propanediol, ethanol and butanol. Gene names coding for the enzymes catalyzing the corresponding reactions are listed in italics. Multiple genes coding for a complexed functional protein are colored blue. Paralogs annotated with the same function and name are noted in parentheses. Asterisks indicate genes found mutated in M150B. Enzyme names are as follows: 1 glycerol dehydratase, 21,3-propanediol dehydrogenase, 3 glycerol dehydrogenase, 4 dihydroxyacetone kinase, 5 triosephosphate isomerase, 6 glyceraldehyde-3-phosphate dehydrogenase, 7 phosphoglycerate kinase, 8 phosphoglycerate mutase, 9 enolase, 10 pyruvate kinase, 11 pyruvate-flavodoxin oxidoreductase, 12 acetyl-CoA acetyltransferase, 13 3-hydroxybutyryl-CoA dehydrogenase, 14 3-hydroxybutyryl-CoA dehydratase, 15 butyryl-CoA dehydrogenase/Etf complex, 16 butyrate-acetoacetate CoA-transferase, 17 aldehydealcohol dehydrogenase, 18 possible pyruvate decarboxylase, $19 \mathrm{NADH}$-dependent butanol dehydrogenase, $20 \mathrm{NADPH}$-dependent butanol dehydrogenase, 21 phosphate acetyltransferase, 22 acetate kinase, 23 phosphate butyryltransferase, 24 butyrate kinase

Acetoacetyl-CoA is converted to acetone by Adc [31]. In Cac, the sol locus, encoded on the pSOL1 megaplasmid [32], contains the adhE1, ctfA, ctfB genes in an operon organization (although recent work in our lab shows that the $c t f A / B$ genes can be also transcribed independently of the $a d h E 1$ gene), and the monocistronic $a d c$ gene in the opposite orientation. There is exists a very similar paralog of the AdhE1 protein also encoded on the Cac pSOL1 megaplasmid, annotated as adhE (CA_P0035), but that protein, although it can catalyze butanol formation, is not involved in the in vivo formation of butanol as it is not expressed under normal solventogenic conditions [33]. The Cpa adhE2 gene is $76 \%$ similar with the Cac adhE1 on the DNA level and $82 \%$ on the amino acid level. Likewise, the $c t f A, c t f B 2$, and $a d c$ genes are similar to their Cac orthologs (Cac ctfA $74 \%$ by DNA, 73 \% by protein; Cac ctfb $71 \%$ by DNA, 71 \% by protein; Cac adc 76 \% by DNA, $84 \%$ by protein, respectively). Cpa has three more annotated adhE genes (adhE1, c05730 [similarities: $73 \%$ DNA, $77 \%$ protein to Cac adhE1]; adhE3, c15660 [70\%
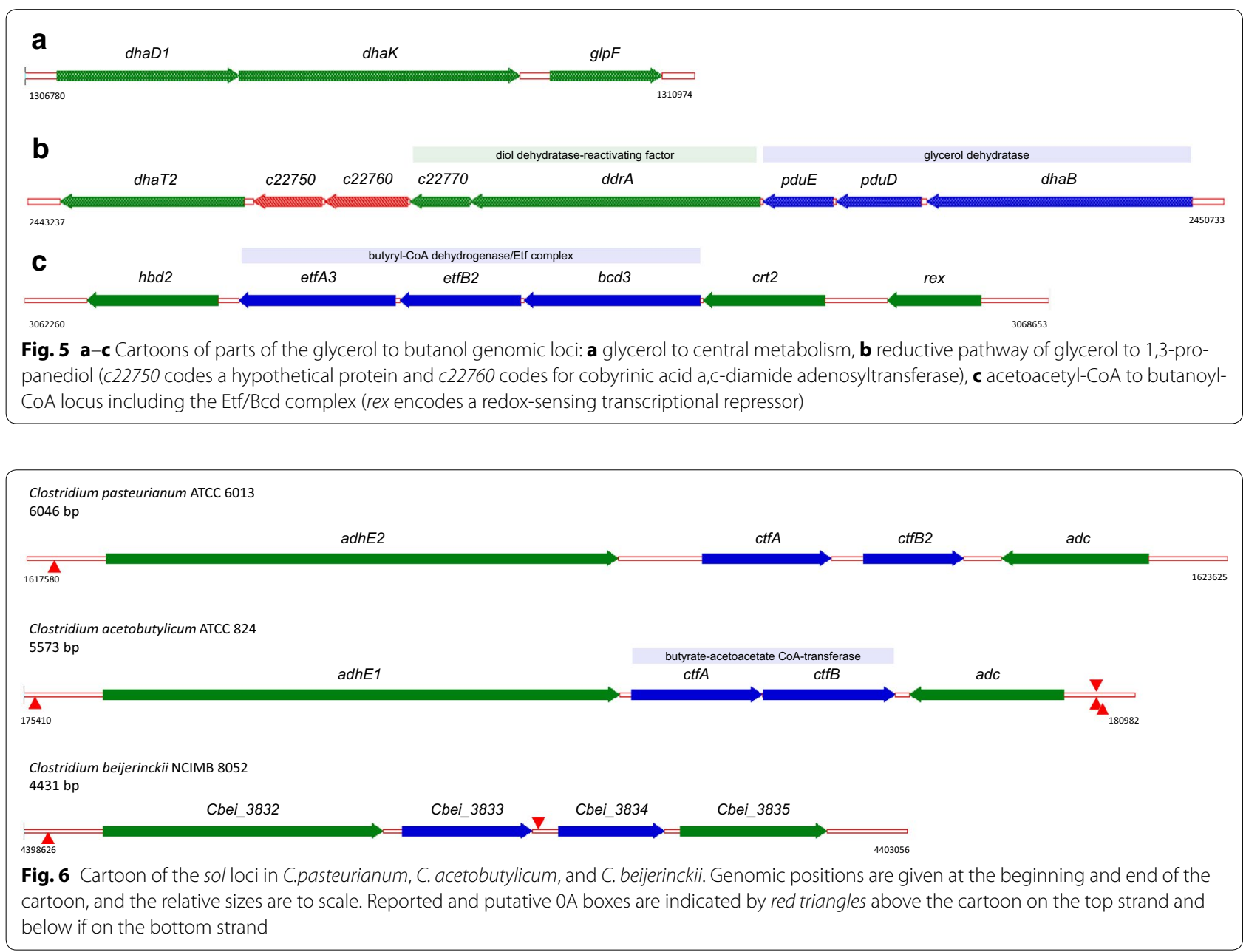


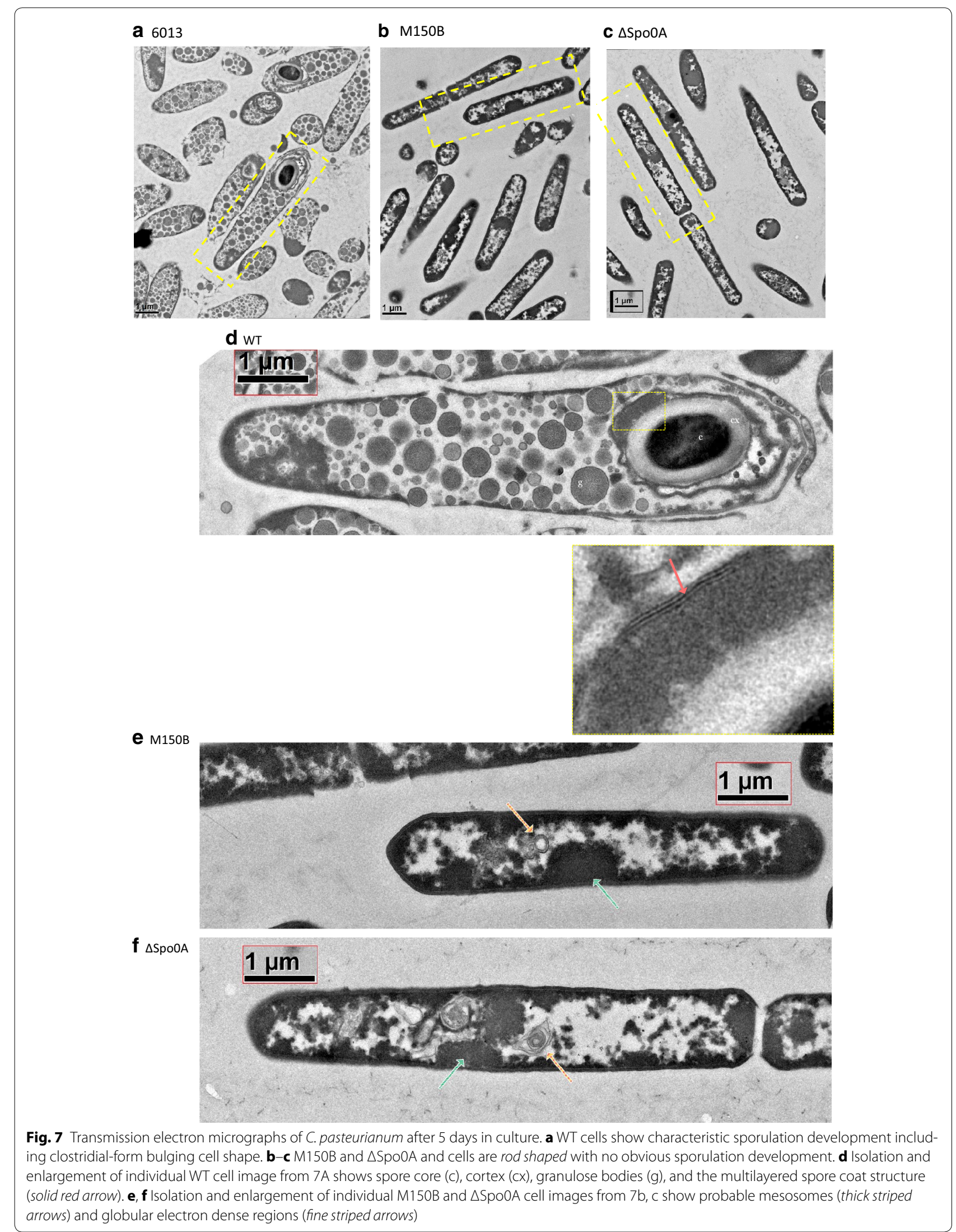


DNA, $64 \%$ protein to Cac adhE]; and adhE4, c28930 [73\% DNA, $76 \%$ protein to Cac adhE1]) and two butanol dehydrogenase genes (bdh1, c04370 [71 \% DNA, $72 \%$ protein to $C a c b d h A$ ] and $b d h 2$, c15980 [46 \% DNA, $39 \%$ protein to $C a c b d h B]$ ) located in different parts of the genome. Notably, Cpa contains an additional set of genes encoding a CoAT (atoD, c08850 [55\% DNA, $46 \%$ protein to $C a c$ ctfA] and ctfB1, c08840 [62\% DNA, $55 \%$ protein to $C a c$ ctfB]). One assumes naming c08850 'atoD' was inspired by the standard Escherichia coli nomenclature, but it might be more appropriately named $c t f A 1$ (with the c15170 gene as $c t f A 2)$. The $k d c$ gene (keto-acid decarboxylase) of $C p a$ (c04400) has $53 \%$ similarity to the pyruvate decarboxylase gene of $C a c$ ( $p d c, 40 \%$ by protein), which catalyzes the conversion of pyruvate to acetaldehyde.

When comparing the sol loci in Cpa and Cac, we observe relatively large gaps between the adhE2, ctfA, and $c t f B 2$ genes in Cpa (432 bp and 162 bp, respectively), while the $C a c$ orthologs are much closer together (only 63 and $5 \mathrm{bp}$ ), indicating a tighter operon structure (Fig. 6). The expression of the Cac adhE1-ctfAB operon has been shown to be controlled by an activated (phosphorylated) Spo0A(34), and a Spo0A-binding site (0A box) has been proposed [26] (Fig. 6). In addition to the Spo0A-binding site, $\mathrm{Cac}$ has putative repeated regulatory elements, which overlap with the 0A box [34]. While $C p a$ has a similar 0A box in this region, these repeated elements do not seem to be present. In addition, $C p a$ has 3 additional $a d h E$ genes, two of which do not have any identifiable $0 \mathrm{~A}$ boxes upstream. This may play a role in butanol formation being unaffected by the loss of Spo0A activity as demonstrated by the inability of the strain to sporulate. Cac also has three putative 0A boxes upstream of the $a d c$ gene. Cpa has none that could be identified. This is notable since Cpa seems to contain all the genetic elements necessary for acetone production (an intact sol locus), it does not produce acetone. This would suggest that the genes for acetone formation may be expressed and used only under specific culture conditions not currently employed in standard laboratory $C p a$ cultures.

The Cbe sol operon differs considerably from $\mathrm{Cac}$ and Cpa (Fig. 6). Its sol operon does not contain a bifunctional $a d h E$ gene as in $C a c$ and $C p a$, but contains a gene coding for an aldehyde dehydrogenase (ald, Cbei_3832). A bifunctional adhE gene (Cbei_0305) is located in another locus. The adc gene (Cbei_3835) is oriented in the same orientation as ald, $\operatorname{ctf} A$, and $c t f B$ and these are all transcribed in a polycistron [35] with a putative $0 \mathrm{~A}$ box upstream.

These differences in the regulation of solventigenic genes between $\mathrm{Cpa}$ and the two classical solventogenic clostridia, $\mathrm{Cac}$ and $\mathrm{Cbe}$, are of fundamental and practical interest. The role of Spo0A in solvent production regulation results in more complex phenotypes, and, notably, strain degeneration and bistability in solvent production [18, 36, 37]. Strain degeneration refers to the simultaneous loss of the ability to sporulate and produce solvents. While bistability in solvent production refers to the different outcomes (high versus low) of solvent production depending on the state of the culture inoculum used. The two phenotypes are linked and are likely related to the complex role of the sporulation-specific sigma factor SigK, which controls both Spo0A expression as well as late sporulation events [36, 38]. Cpa appears to be shielded from such phenotypic complexities, which result in performance-limiting practical bioprocessing issues [31].

To sum, mapping of the proteins that are responsible for solvent formation on the Cpa genome, and comparative analysis against the corresponding genes in the two well-studied Clostridium solventogens, $\mathrm{Cac}$ and $\mathrm{Cbe}$, demonstrated distinct genetic organizations and regulatory elements that would explain the observed phenotypic differences. The latter include the fact that, in contrast to $\mathrm{Cac}$ and $\mathrm{Cbe}$, butanol formation in $\mathrm{Cpa}$ is not controlled by Spo0A, and is in fact growth associated (Fig. 2) rather than a stationary-phase phenomenon.

\section{New findings from revisiting the SMRT-sequencing-enabled Cpa-DNA methylation analysis} Using SMRT sequencing it is possible to interrogate the native methylome of the genome as no amplification steps occur prior to sequencing. As the DNA is being sequenced, modification to bases result in a delay in the called bases, called the interpulse duration ratio (IPD) [39]. Using the PacBio RS Modification and Motif Analysis (MAMA) protocol, we observe in both the WT and M150B genomes the previously reported $N^{6}$-methyladenine modification motifs associated with Type II and Type I restriction modification systems in $\mathrm{Cpa}$ (m-6A modifications: $5^{\prime}-\mathrm{GA}^{\mathrm{m}} \mathrm{TC}-3^{\prime}$ and $5^{\prime}-\mathrm{AA}^{\mathrm{m}} \mathrm{GNNNNNCTCC-}{ }^{\prime}$, respectively) [15]. The MAMA protocol also returned two previously unreported $N^{6}$-methyladenine modification motifs $5^{\prime}$-GRTAAA ${ }^{\mathrm{m}} \mathrm{G}-3^{\prime}$ and $5^{\prime}$-CAAAAA ${ }^{\mathrm{m}} \mathrm{R}-3^{\prime}$ in both sequenced genomes ( $R=G$ or $A$; Table 2$)$.

Methylcytosine modifications are more difficult to determine compared to m-6A [39]. Cpa carries a Type II restriction endonuclease identified as a barrier to plasmid transformation as it recognizes and cuts $5^{\prime}$-CGCG$3^{\prime}$ motifs $[11,40]$. The MAMA protocol returned two different motifs containing $5^{\prime}$-CGCG-3' for the WT and M150B (5'-CGC ${ }^{\mathrm{m}}$ GNNNANNNTNNANA-3' and $5^{\prime}$-MNNNC ${ }^{\mathrm{m}}{ }^{\mathrm{GCGAANANT}}-3^{\prime}$, respectively), but these seem to be overspecified since there are only 11 and 14 of these sequences in the Cpa genome, respectively. Furthermore, the modified base differs between the two. By 
Table 2 Methylation data and analysis

\begin{tabular}{|c|c|c|c|c|c|c|c|c|}
\hline Motif & $\begin{array}{l}\text { Modified } \\
\text { position }\end{array}$ & Type & $\begin{array}{l}\% \text { motifs } \\
\text { detected }\end{array}$ & $\begin{array}{l}\text { \# of motifs } \\
\text { detected }\end{array}$ & $\begin{array}{l}\text { \# of motifs } \\
\text { in genome }\end{array}$ & $\begin{array}{l}\text { Mean modifi- } \\
\text { cation QV }\end{array}$ & $\begin{array}{l}\text { Mean motif } \\
\text { coverage }\end{array}$ & Partner motif \\
\hline GRTAAAG & 6 & m6A & 99.65 & 2579 & 2588 & 87.0 & 55.4 & \\
\hline AAGNNNNNCTCC & 2 & $\mathrm{~m} 6 \mathrm{~A}$ & 99.61 & 511 & 513 & 93.1 & 59.4 & GGAGNNNNNCTT \\
\hline GGAGNNNNNCTT & 3 & $\mathrm{~m} 6 \mathrm{~A}$ & 99.03 & 508 & 513 & 88.1 & 58.0 & AAGNNNNNCTCC \\
\hline GATC & 2 & $\mathrm{~m} 6 \mathrm{~A}$ & 99.14 & 13,348 & 13,464 & 85.8 & 58.4 & GATC \\
\hline CAAAAAR & 6 & $\mathrm{~m} 6 \mathrm{~A}$ & 97.10 & 3786 & 3899 & 74.0 & 56.3 & \\
\hline
\end{tabular}

analyzing the IPD data directly, however, we observed that the average IPD for the first cytosine of $5^{\prime}-\mathrm{C}^{\mathrm{m}} \mathrm{GCG}$ $3^{\prime}(1.25)$ is significantly higher than the IPD in $5^{\prime}-C^{m}-3^{\prime}$ $(0.86)$ and $5^{\prime}-\mathrm{C}^{\mathrm{m}} \mathrm{G}-3^{\prime}(0.89)$ (two-sided heteroscedastic $t$ test $p$ values of $9.0 \mathrm{E}-7$ and $4.5 \mathrm{E}-6$, respectively), indicating this motif is likely modified. The IPD for the second cytosine in $5^{\prime}-\mathrm{CGC}^{\mathrm{m}} \mathrm{G}-3^{\prime}(1.11)$ is also significantly higher than in $5^{\prime}-C^{\mathrm{m}}-3^{\prime}$ and $5^{\prime}-\mathrm{C}^{\mathrm{m}} \mathrm{G}-3^{\prime}$ ( $p$ values of $1.2 \mathrm{E}-3$ and $4.1 \mathrm{E}-3$, respectively), but it indicates lesser frequency of methylation on the second cytosine.

We identified bepIM (c05910) on the Cpa genome encoding the modification methylase BepI. We codon optimized the Cpa bepIM for E. coli and had it synthesized and cloned into a plasmid (pCpaDcm2.0, Additional file 1: Table S2, DNA 2.0). Prior to transformation, we first methylated all shuttle plasmids by transforming them into an $E$. coli methylation strain carrying pCpaDcm2.0. No successful transformations were performed without this prior in vivo methylation. Plasmid transformation in Cpa has been shown previously using the heterologous M.FnuDII methyltransferase (5'$\left.\mathrm{C}^{\mathrm{m}} \mathrm{GCG}-3^{\prime}\right)$ to evade the endogenous restriction enzyme [11]. While methylation of plasmids with heterologous genes is effective, methylome analysis and synthetic expression of the native methyltransferase enzymes is a generalizable method to transform bacteria with an unknown endonuclease recognition sequence.

\section{Construction of Cpa SpoOA knockout confirms that Spo0A inactivation is responsible for conferring tolerance to and better growth on crude glycerol, as well as enhanced growth-associated butanol production}

The mutation in $5 p o O A$ was the most conspicuous of all identified, so we decided to test the hypothesis that this deletion was the primary cause of the changes in phenotype we observed. We used the MazF knockout system [41] to design a $200 \mathrm{bp}$ deletion at the start of the spo0A gene, including the ribosomal-binding site, start codon, and 60 codons. The design replaces this $200 \mathrm{bp}$ with a chloramphenicol acetyltransferase gene (cat) with FRT sites on either side. The recombination plasmid
(pKOmazF-Spo0A) contains regions of homology (sized 536 and $506 \mathrm{bp}$ ) flanking either side of the cat gene and FRT sites. The plasmid was constructed in the manner as previously described [41] and transformed via the previously reported protocol [11] with the exception of the methylation method (see above). Successful recombination was confirmed via size verification of the insert via PCR and agarose gel imaging from three isolated colonies that grew on solid 2xYTG supplemented with thiamphenicol and lactose. Recombination plasmid removal was performed with serial transfers in unselective media and confirmed by replica plating. The integrated cat gene was removed with the transformed p94-FLP containing the flippase gene as described [41] and confirmed by PCR and Sanger sequencing. Briefly, Cpa $\triangle s p o 0 A:: T h R+$ p94Flp was grown in liquid media supplemented with erythromycin at $30{ }^{\circ} \mathrm{C}$ and subsequently plated on solid $2 \mathrm{xYTG}+$ Em media. Replica plating confirmed thiamphenicol sensitivity. Loss of p94-Flp was confirmed by replica plating after two serial transfers in unselective media.

To confirm the sporulation deficient phenotype was due to the deletion in the spoOA gene, the WT, M150B, and $\triangle \mathrm{SpoOA}$ strains were imaged by transmission electron microscopy (TEM). The three strains were cultured for 5 days before cells were prepared for TEM analysis. As expected, the WT strain (Fig. 7a, d) displayed the characteristic features of sporulating solventogenic Clostridium cells (and notably of Cac cells [18, 42]), showing spore development at different maturation stages, and an unusually large number of the characteristic granulose bodies for all cells compared to other Clostridium organisms. The granulose bodies appear as lightly electron dense in an electron translucent background, which is also somewhat unusual compared to other solventogenic Clostridium cells.

The $\mathrm{M} 150 \mathrm{~B}$ and $\triangle \mathrm{Spo} 0 \mathrm{~A}$ strains display no granulose bodies, septum, or forespore structures, showing only vegetative cells (Fig. $7 \mathrm{~b}, \mathrm{c}$ ) with no bulging structures characteristic of sporulating clostridial-form cells [18, 42]. All cells displayed in their core irregular electron 
translucent regions, many cells contain one or two globular lightly electron dense features, all surrounded by an electron dense region that defines the cell shape (Fig. 7e, f). We also observed identifiable membranous structures (Fig. 7e, f), which may be mesosomes, an artifact of the chemical fixation process [43]. The M150B and $\Delta$ Spo0A cells look similar to the $\Delta$ sigK Cac cells [38], where sporulation has been blocked just prior to Spo0A expression and activation, and also similar to the Cac cells with an inactivated sigF gene [37]. In Clostridium organisms [36],
SigK acts both very early (prior to Spo0A expression) and very late in sporulation, while SigF acts just after Spo0A activation.

We tested the growth of the knockout strain in $100 \mathrm{~g} / \mathrm{L}$ crude glycerol along with the wild-type and the M150B mutant. The M150B and $\triangle$ Spo0A strains show a markedly reduced lag time compared to the WT strain (Fig. 8a). Unlike previous results (Fig. 2), the WT strain achieves similar OD to the evolved strain after $48 \mathrm{~h}$. Metabolite analysis by HPLC show improved butanol
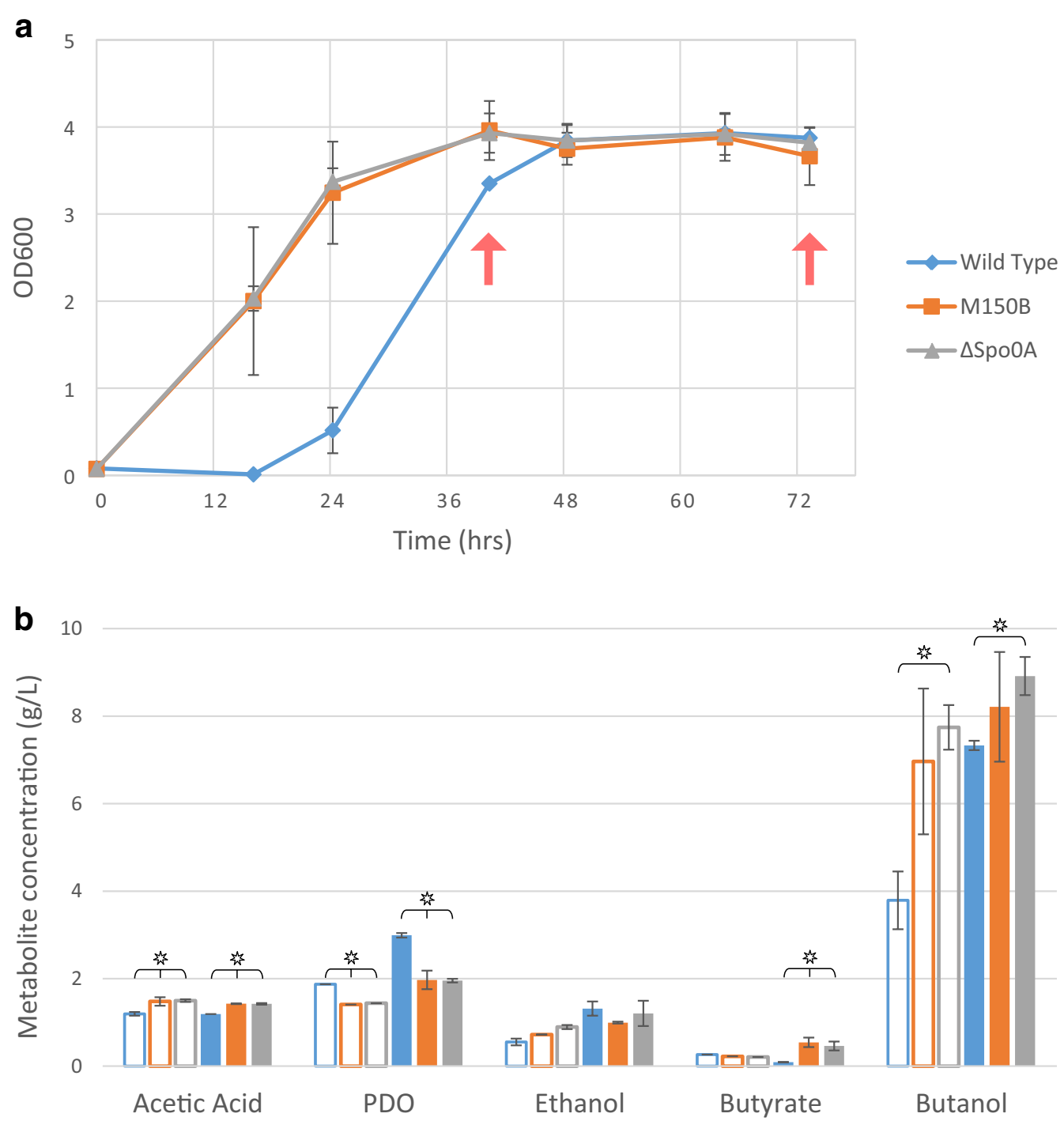

$\square 6013 \square \mathrm{M} 150 \mathrm{~B} \square \Delta \mathrm{SpoOA}$

Fig. 8 Growth and metabolite analysis of C. pasteurianum WT, M150B, and $\triangle S$ Spo0A strains in CGM with $100 \mathrm{~g} / \mathrm{L}$ crude glycerol. a OD 600 shows extended lag phase of WT (blue diamonds) compared to M150B (orange squares) and $\triangle S$ Spo A (gray triangles). Red arrows indicate samples taken for analysis. b Metabolite profiles at $40 \mathrm{~h}$ (hollow) and $73 \mathrm{~h}$ (solid) of WT (blue), M150B (orange), and $\triangle$ Spo0A (gray). Error bars represent standard deviation, two biological replicates. Stars indicate $t$ test $p$ value $<0.05$ between WT and either or both M150B and $\triangle$ Spo0A. Note that the initial CGM media contains $1.8 \mathrm{~g} / \mathrm{L}$ acetic acid 
formation for the Spo0A knockout strain (Fig. 8b). The WT strain produced $50 \%$ more PDO than the M150B and $\triangle \mathrm{Spo} 0 \mathrm{~A}$ strain, which is consistent with what was seen previously. These data show that the observed phenotype of the M150B strain in tolerating higher levels of crude glycerol, faster growth and reduced lag time on glycerol and improved levels of butanol formation can be recapitulated by Spo0A inactivation.

\section{Discussion}

It has been suggested that $\mathrm{Cpa}$ 's ability to consume glycerol as the sole carbon source is likely due to its reductive PDO pathway. As glycerol is more reduced than glucose, more reducing equivalents are generated to get to glyceraldehyde-3-phosphate, necessitating some glycerol reduction to PDO [8]. The Cac genome does not contain the PDO producing pathway, which is likely the reason it cannot use glycerol as a sole substrate [7].

Cpa contains multiple paralogs of genes in the glycerol to butanol pathway: glycerol dehydrogenase (4 annotated paralogs), aldehyde-alcohol dehydrogenase ( $a d h E)$ [4], pyruvate-flavodoxin oxidoreductase [3], acetoaceate CoA-transferase [2], 1,3-propanediol dehydrogenase [2], NADH-dependent butanol dehydrogenase [2], and NADPH-dependent butanol dehydrogenase [2]. The large number of paralogs of these core genes may account for the observed high rates of growth and product formation. It has been noted that Cpa fermentation products vary under similar conditions, and was thus theorized that the regulation of fermentation related genes is not very strict [8].

Using whole-genome sequencing we are able to fully assess the differences between the parent and evolved daughter strain, M150B. We showed that inactivation of the master regulator of sporulation in C. pasteurianum, and all Clostridium organisms [36], Spo0A, confers an increased tolerance to crude glycerol stress. As M150B was superior to WT in pure glycerol as well, another selection mechanism seems to have been fast growth on glycerol. Spo0A is a highly conserved protein, which is the master regulator of sporulation in Clostridium and Bacillus [36, 44]. Spo0A comprises a phosphoacceptor domain and a transcription activation, or 'effector', domain. Phosphorylation of the phosphoacceptor domain affects transcription, both positively and negatively, for a large number of genes by binding to Spo0Abinding motif (the '0A box', 5 '-TGNCGAA-3') $[25,26]$. The 0A box can be found in the promoter region of a variety of stationary-phase-related genes controlled by the activated (phosphorylated) Spo0A, including, in Clostridium organisms, the gene for the first sporulation-specific sigma factor SigF [36]. Blocking the expression of SigF blocks the expression of the all downstream sporulation-specific sigma factors (SigG, E and K), and this is the mechanism by which Spo0A inactivation abolishes sporulation [36].

The effector domain contains a DNA-binding helixturn-helix region along with a $\sigma^{\mathrm{A}}$ activator region (Fig. 3) [25]. Mutations of B. subtilis' spoOA in this region have been shown to have lower or failed activation from $\sigma^{\mathrm{A}}$ promoters and these mutants are asporogenous [25]. The activation of SpoOA in $\mathrm{Cac}$ has been shown to be dependent on one of two histidine kinase mediated phosphorylation pathways: one involving a single gene Cac_O323 (having $32 \%$ identical ortholog Cpa_c33080) and the other necessarily involving both the genes Cac_0903 and Cac_3319 (with 38 and $27 \%$ identical orthologs Cpa c33080 and Cpa_c19640, respectively) [45]. A Cac_3319 mutant showed significantly reduced sporulation activity as well as increased butanol production [45, 46], showing solvent production regulation to be a highly complex and relatively poorly understood process.

The presence of Spo0A has been shown to be essential for solventogenesis in Cac and C. beijerinckii [26]. Overexpression in Cac leads to early onset of sporulation and solventogenesis [22], as well as to increased butanol tolerance and prolonged metabolism as a result of large and complex changes in the transcriptional program of the cells [47]. Strong butanol production in the $C p a \Delta$ SpoOA shows that although $C p a$ is closely related to $C a c$, solvent production is not regulated in the same manner. Beyond the present findings that demonstrate that SpoOA is not necessary for butanol formation, there are also several other distinct differences worth noting. First, butanol formation in $\mathrm{Cpa}$ is growth associated in contrast to $\mathrm{Cac}$ and $\mathrm{Cbe}$, where butanol production occurs as active growth ceases and continues into the stationary phase of the culture [42]. Since little butyrate and no acetate is formed in Cpa fermentations (Fig. 2), acid and notably butyrate [48] (or butyryl-P [49]) is not obviously a trigger for solventogenesis as in $\mathrm{Cac}$ and other solventogenic Clostridium organisms. Related to the latter is the fact that, as extensively discussed [9], in Cpa, there is no acetone formation, which characterizes solvent formation in $\mathrm{Cac}$ and $\mathrm{Cbe}$, where it accompanies acid re-uptake. It is still a mystery why Cpa produces no acetone despite the fact that, as discussed above, all the genes for its formation are present on the Cpa genome, some with several paralogs. In this context, it is noteworthy that $\mathrm{Cac}$, when grown on glucose in the presence of glycerol in continuous culture, it forms no acetone [7]. The authors of Ref. [7] noted that this is mechanistically similar to the impact of gassing continuous culture of $\mathrm{Cac}$ with carbon monoxide [50], which inhibits hydrogen production. They concluded [7] that: "Acetone formation requires no reduction energy, and it appears that the cellular control 
mechanisms avoid its production in order to maximize the regeneration of NAD $(\mathrm{P})$ in the reduced nucleotideconsuming pathway".

\section{Conclusion}

In conclusion, this present study provides a genomic understanding of the unique phenotypic Cpa characteristics, and strengthens the case for using Cpa as a butanol producer. It has the advantage of growth-associated butanol production with little concomitant acid and no acetone production. Growth-associated butanol production would in principle enable the development of continuous or continuous-like processes, which are difficult to develop with the well-known solventogens like $\mathrm{Cac}$ and $\mathrm{Cbe}$ due to the wellknown degeneration phenotype [31, 36]. As was shown recently [9], Cpa strains and culture media can be readily developed to enable $\mathrm{Cpa}$ cultures of high cell densities producing high titers of butanol with very good productivities. The present finding would further increase the appeal of such Cpa strains, which can become even more productive with further strain engineering, such as for minimizing or eliminating PDO formation. It has been documented [51] that, as hosts for the production of chemicals and fuels, Clostridium organisms have the major advantage of using a broad spectrum of substrates deriving from biomass (hexoses, pentoses, oligosaccharides, xylans), and although not extensively studied, Cpa does not appear to be an exception to this assessment. Its genome codes the necessary genes that would make it an effective user of such a broad spectrum of substrates, on top of its powerful ability to effectively and quickly utilize crude glycerol, alone and in combination with other carbohydrates.

\section{Methods}

Bacterial growth and maintenance conditions

Strains used in this study are listed in Table 3. C. pasteurianum ATCC 6013 was grown anaerobically at $37{ }^{\circ} \mathrm{C}$ in liquid CGM (per liter of distilled water: $\mathrm{KH}_{2} \mathrm{PO}_{4}$, $0.75 \mathrm{~g} ; \mathrm{K}_{2} \mathrm{HPO}_{4}, 0.75 \mathrm{~g} ; \mathrm{MgSO}_{4}$ [anhydrous], $0.348 \mathrm{~g}$; $\mathrm{MnSO}_{4} \cdot \mathrm{H}_{2} 0,0.01 \mathrm{~g} ; \mathrm{FeSO} 4 \cdot 7 \mathrm{H}_{2} 0,0.01 \mathrm{~g} ; \mathrm{NaCl}, 1.0 \mathrm{~g}$; asparagine, $2.0 \mathrm{~g}$; yeast extract, $5.0 \mathrm{~g}$; sodium acetate, 2.46 g; $\left(\mathrm{NH}_{4}\right) 2 \mathrm{SO}_{4}, 2.0 \mathrm{~g}$; and para-aminobenzoic acid [PABA], $0.04 \mathrm{~g}$; titrated to $\mathrm{pH}$ 6.8) with, unless otherwise stated, $80 \mathrm{~g} / \mathrm{L}$ glucose as the main carbon source. C. pasteurianum ATCC 6013 was grown anaerobically at $37^{\circ} \mathrm{C}$ on solid 2xYTG (pH 6.5) agar plates [52] supplemented with the appropriate antibiotic (erythromycin at $40 \mu \mathrm{g} /$ $\mathrm{ml}$ for solid-medium plates and $100 \mu \mathrm{g} / \mathrm{ml}$ for liquid medium or thiamphenicol at $10 \mu \mathrm{g} / \mathrm{ml})$. C. pasteurianum strains were stored at $-85^{\circ} \mathrm{C}$ in CGM supplemented with $15 \%$ glycerol and were revived by plating onto 2xYTG (pH 6.5) agar plates. Escherichia coli strains were grown aerobically at $37{ }^{\circ} \mathrm{C}$ in liquid LB medium or on solid LB
Table 3 Strains and plasmids used in this study

\begin{tabular}{lll}
\hline & Description & Source \\
\hline $\begin{array}{l}\text { Strain } \\
\text { Cpa ATCC 6013 }\end{array}$ & $\begin{array}{c}\text { Wild-type Clostridium pasteuri- } \\
\text { anum }\end{array}$ & ATCC \\
Cpa M150B & $\begin{array}{c}\text { Mutant isolated from crude } \\
\text { glycerol selection }\end{array}$ & This study \\
Cpa $\triangle$ Spo0A & $\begin{array}{c}\text { Constructed Spo0A deficient } \\
\text { strain }\end{array}$ & This study \\
NEB Turbo & $\begin{array}{c}\text { Cloning strain for DNA manipula- } \\
\text { tion }\end{array}$ & NEB \\
Plasmid & Methylating plasmid & \\
pCpaDcm2.0 & $\begin{array}{l}\text { General recombination plasmid } \\
\text { pKO-mazF }\end{array}$ & Al-Hinai et al. [41] \\
pKO-mazF-spo0A & $\begin{array}{l}\text { Knockout plasmid targeting } \\
\text { Spo0A }\end{array}$ & This study \\
p94-Flp & Flippase plasmid for ThR removal & Al-Hinai et al. [41] \\
\hline
\end{tabular}

agar plates supplemented with the appropriate antibiotic (50 $\mu \mathrm{g} / \mathrm{mL}$ ampicillin, $35 \mu \mathrm{g} / \mathrm{mL}$ chloramphenicol, $25 \mu \mathrm{g} /$ $\mathrm{mL}$ kanamycin). E. coli strains were stored at $-85^{\circ} \mathrm{C}$ in LB medium supplemented with $15 \%$ glycerol.

\section{Analytical methods}

Cell density was measured at $600 \mathrm{~nm}$ using a Beckman Coulter DU 730 spectrophotometer. Samples were diluted with the appropriate medium to maintain readings in the linear range (below 0.40). DNA concentrations and purities were measured at 260 and $280 \mathrm{~nm}$ using a NanoDrop (Wilmington, DE, USA) spectrophotometer.

Culture supernatants were analyzed for acetate, butyrate, acetone, butanol, ethanol, acetoin, 1,3-propanediol, and glycerol concentrations using an Agilent LC high-performance liquid chromatography system (with 1260 Infinity standard autosampler, isocratic pump, refractive index detector, and in-line vacuum degasser) and Agilent ChemStation software. A Bio-Rad Aminex HPX-87H anion exchange column was used with a mobile phase of $0.05 \mathrm{mM}$ sulfuric acid flowing at $0.50 \mathrm{~mL} / \mathrm{min}$. No acetoin was detected in any cultures. Lactic acid concentration in the supernatant was determined by a YSI 2700 biochemistry analyzer (YSI, Yellow Springs, OH, USA).

\section{Growth and metabolite assays}

Cpa overnight CGM cultures were inoculated with individual colonies taken from solid media. For glycerol studies, a starter culture of CGM supplemented with $60 \mathrm{~g} / \mathrm{L}$ molecular biology grade glycerol (no glucose) was inoculated with overnight culture to an $\mathrm{OD}=0.020-0.050$ and allowed to grow to mid-exponential phase (OD 0.4-0.8). Experimental cultures of 20-80 mL CGM supplemented with $60 \mathrm{~g} / \mathrm{L}$ molecular biology grade glycerol or $100 \mathrm{~g} / \mathrm{L}$ 
crude glycerol were inoculated from starter cultures to an $\mathrm{OD}=0.070$. All media was stored at $37^{\circ} \mathrm{C}$ anaerobically for at least $48 \mathrm{~h}$ prior to use. Samples were taken for turbidity and metabolite analysis simultaneously. For metabolite analysis, samples were centrifuged for $1 \mathrm{~min}$ at $16,000 \mathrm{rcf}$, and the supernatant was removed and stored at $-20{ }^{\circ} \mathrm{C}$ until analyzed. Samples were filtered with a $0.22 \mu \mathrm{m}$ syringe filter prior to downstream analysis.

\section{Whole-genome SMRT sequencing}

High molecular weight genomic DNA was isolated from C. pasteurianum ATCC 6013 and M150B strains using Genomic-tip 100/G (QIAGEN) according the manufacturer's instructions. Single molecule real time sequencing (SMRT) sequencing was performed at the University of Delaware DNA Sequencing and Genotyping Center. SMRTbell DNA libraries were constructed according to the Pacbio standard protocol. Template preparation was performed using BluePippin (Sage Science) size-selection system including DNA damage and end repair steps and ligation to hairpin adapters. Both libraries were sizeselected starting at $7 \mathrm{~kb}$ and with an average library size of $20 \mathrm{~kb}$ as measured by Fragment Analyzer (Advanced Analytical Technologies, Inc). Sequencing was performed on PacBio RSII (Pacific Biosciences, Menlo Park, California) instrument using $\mathrm{P} 4-\mathrm{C} 2$ chemistry, mag-bead loading and 3-h movie time. To identify consensus and variant sequences, quality-filtered reads were mapped against a reference sequence (accession number CP009267 [20]) using the RS Resequencing protocol within the SMRT Analysis version 2.3 through the SMRT Portal. The RS Modification and Motif Analysis protocol was used to identify base modifications and methyltransferase recognition motifs.

\section{Knockout of Cpa spoOA}

Plasmids used in this study are listed in Table 3. Oligonucleotides were synthesized by Integrated DNA Technologies (IDT, Iowa City, IA, USA) and are listed in Additional file 1: Table S2. Two $\sim 500$ bp regions of homology designed to surround the ribosomal-binding site and first section of the spoOA gene (including the start codon) were amplified with primers $140 \& 141$ and $142 \& 143$. These were sequentially cloned into the pKOmazF vector [41] using SphI \& AgeI and MluI \& NcoI to generate $\mathrm{pKO}-\mathrm{mazF}-\mathrm{spo0A}$. Successful cloning at each stage was confirmed by PCR and Sanger sequencing.

Newly constructed plasmids were transformed into E. coli Turbo (NEB) cells and subsequently isolated and confirmed via PCR confirmation and Sanger sequencing. Immediately prior to transformation of plasmids into Cpa, plasmids were electroporated with E. coli ER1821(pCpaDcm2.0) (NEB). For plasmid methylation, cultures were supplemented with $1 \mathrm{mM}$ rhamnose at least $4 \mathrm{~h}$ prior to plasmid extraction via miniprep. At least $500 \mathrm{ng}$ of methylated plasmids were subsequently transformed into $\mathrm{Cpa}$ as described by Pyne et al. [11].

The bepIM gene was synthetically constructed (DNA 2.0, Menlo Park, CA, USA) for optimized codon usage in E. coli (see Additional file 1: Table S1). The bepIM gene was cloned into plasmid pD881 (pCpaDcm2.0), which uses a rhamnose inducible promoter.

\section{Microscopy}

For light microscopy, samples taken from 6 day old CGM culture were pelleted and washed twice with $1 \% \mathrm{w} / \mathrm{v}$ $\mathrm{NaCl}$. Slides were imaged using a Leica widefield microscope with phase contrast to distinguish cell morphology.

For transmission electron microscopy, Cpa strains cultured for 5 days in CGM were pelleted and the supernatant was removed. The bacterial pellet was treated with $16 \%$ paraformaldehyde and $8 \%$ glutaraldehyde to the culture medium for a final concentration of $2 \%$ paraformaldehyde and $2 \%$ glutaraldehyde in $0.1 \mathrm{M}$ sodium cacodylate buffer and inverted multiple times to mix. Cultures were fixed for $2 \mathrm{~h}$ at room temperature, pelleted and resuspended in buffer. The cells were then pelleted and embedded with $4 \%$ low melting point agarose and cut into $1-2 \mathrm{~mm}^{3}$ cubes. Samples were washed for $15 \mathrm{~min}$ thrice in $0.1 \mathrm{M}$ sodium cacodylate buffer ( $\mathrm{pH}$ 7.4) before fixation for $2 \mathrm{~h}$ in $1 \%$ osmium tetroxide solution. Samples were then dehydrated in increasing concentrations of acetone washes for $15 \mathrm{~min}$ each $(25,50,75,95,100,100 \%)$. The samples were infiltrated with 50/50 mixture of acetone/n-BGE for $30 \mathrm{~min}$, then infiltrated with $100 \% \mathrm{n}$-BGE for an additional $30 \mathrm{~min}$. Samples were infiltrated with Quetol resin in increasing concentrations with n-BGE as diluent: $25 \%$ overnight, $50 \%$ for $8 \mathrm{~h}, 75 \%$ overnight, $100 \%$ for $8 \mathrm{~h}, 100 \%$ overnight, and $100 \%$ for $8 \mathrm{~h}$. Samples were embedded in BEEM capsules with fresh resin and polymerized for $48 \mathrm{~h}$ at $60^{\circ} \mathrm{C}$. Blocks were sectioned and imaged as described previously [42]. All microscopy imaging was performed at Delaware Biotechnology Institute BioImaging Center.

\section{Additional file}

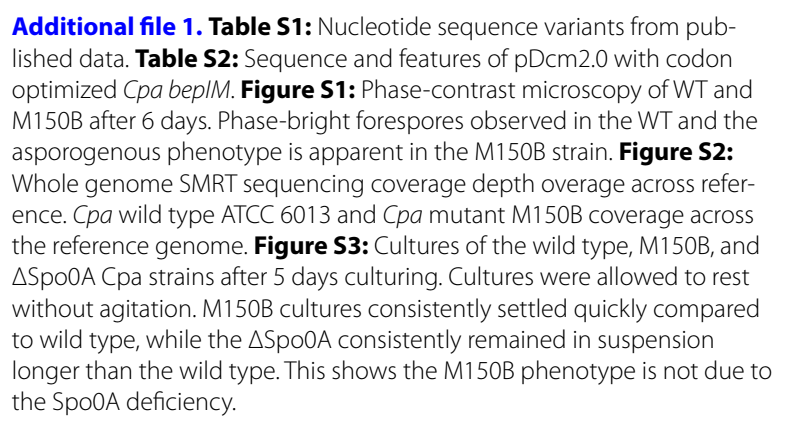




\section{Abbreviations}

Cpa: Clostridium pasteurianum; PDO: 1,3-propanediol; SMRT: single molecule real-time; WT: wild type; NTG: $N$-methyl- $N^{\prime}$-nitro- $N$-nitrosoguanidine; CGM: clostridial growth media; Cac: C. acetobutylicum; Cbe: C. beijerinckii; IPD: interpulse duration ratio; MAMA: modification and motif analysis.

\section{Authors' contribution}

NRS designed experiments with ETP and carried out growth and metabolite experiments, whole-genome sequencing and analysis, microscopy experiments, genetic knockout construction, and wrote the manuscript with ETP. KPV performed whole-genome sequencing and analysis. TSG performed genome sequencing analysis and laboratory preparation procedures. ETP designed experiments and wrote the manuscript with NRS. All authors read and approved the final manuscript.

\section{Author details}

${ }^{1}$ Department of Chemical and Biomolecular Engineering and the Delaware Biotechnology Institute, University of Delaware, 15 Innovation Way, Newark, DE 19711, USA. ${ }^{2}$ Department of Biological Sciences, University of Delaware, Newark, USA.

\section{Acknowledgements}

This work was supported by the Delaware Bioscience Center for Advanced Technology. NRS is supported by an NIH NRSA grant. The authors acknowledge the helps of Shannon Modla in the Delaware Biotechnology Institute Bio-Imaging Facility for the electron microscopy and Olga Shevchenko in the University of Delaware DNA Sequencing and Genotyping Center for the PacBio SMRT sequencing.

\section{Competing interests}

The authors declare that they have no competing interests.

Received: 16 October 2015 Accepted: 3 December 2015 Published online: 24 December 2015

\section{References}

1. Johnson DT, Taconi KA. The glycerin glut: options for the value-added conversion of crude glycerol resulting from biodiesel production. Environ Prog. 2007;26(4):338-48 (PubMed PMID: WOS:000251481200003. English)

2. Taconi KA, Venkataramanan KP, Johnson DT. Growth and Solvent Production by Clostridium pasteurianum ATCC (R) 6013 (TM) Utilizing Biodiesel-Derived Crude Glycerol as the Sole Carbon Source. Environ Prog Sustain. 2009;28(1):100-10 (PubMed PMID: WOS:000269843300012. English)

3. Yazdani SS, Gonzalez R. Anaerobic fermentation of glycerol: a path to economic viability for the biofuels industry. Curr Opin Biotechnol. 2007;18(3):213-9.

4. Yang F, Hanna MA, Sun R. Value-added uses for crude glycerol_-a byproduct of biodiesel production. Biotechnol Biofuels. 2012;5:13 (PubMed PMID: 22413907. Pubmed Central PMCID: 3313861).

5. Jensen TO, Kvist T, Mikkelsen MJ, Westermann P. Production of 1,3-PDO and butanol by a mutant strain of Clostridium pasteurianum with increased tolerance towards crude glycerol. AMB Express. 2012;2(1):44 (PubMed PMID: 22901717. Pubmed Central PMCID: 3492062)

6. Jensen TO, Kvist T, Mikkelsen MJ, Christensen PV, Westermann P. Fermentation of crude glycerol from biodiesel production by Clostridium pasteurianum. J Ind Microbiol Biotechnol. 2012;39(5):709-17.

7. Vasconcelos I, Girbal L, Soucaille P. Regulation of carbon and electron flow in Clostridium acetobutylicum grown in chemostat culture at neutral pH on mixtures of glucose and glycerol. J Bacteriol. 1994;176(5):144350 (PubMed PMID: 8113186. Pubmed Central PMCID: 205211).

8. Biebl H. Fermentation of glycerol by Clostridium pasteurianumbatch and continuous culture studies. J Ind Microbiol Biotechnol. 2001;27(1):18-26.

9. Malaviya A, Jang YS, Lee SY. Continuous butanol production with reduced byproducts formation from glycerol by a hyper producing mutant of Clostridium pasteurianum. Appl Microbiol Biotechnol. 2012;93(4):1485-94 (PubMed PMID: WOS:000300310100012).
10. Dobson R, Gray V, Rumbold K. Microbial utilization of crude glycerol for the production of value-added products. J Indus Microbiol Biotechnol. 2012;39(2):217-26 (PubMed PMID: 21948485. Epub 2011/09/29. eng).

11. Pyne ME, Moo-Young M, Chung DA, Chou CP. Development of an electrotransformation protocol for genetic manipulation of Clostridium pasteurianum. Biotechnol Biofuels. 2013;6(1):50 (PubMed PMID: 23570573. Epub 2013/04/11. Eng)

12. Venkataramanan KP, Boatman JJ, Kurniawan $Y$, Taconi KA, Bothun GD, Scholz C. Impact of impurities in biodiesel-derived crude glycerol on the fermentation by Clostridium pasteurianum ATCC 6013. Appl Microbiol Biotechnol. 2012;93(3):1325-35.

13. Papanikolaou S, Ruiz-Sanchez P, Pariset B, Blanchard F, Fick M. High production of 1,3-propanediol from industrial glycerol by a newly isolated Clostridium butyricum strain. J Biotechnol. 2000;77(2-3):191-208.

14. Furusawa $\mathrm{H}$, Koyama N. Effect of fatty acids on the membrane potential of an alkaliphilic bacillus. Curr Microbiol. 2004;48(3):196-8.

15. Pyne ME, Moo-Young M, Chung DA, Chou CP. Expansion of the genetic toolkit for metabolic engineering of Clostridium pasteurianum: chromosomal gene disruption of the endogenous CpaAl restriction enzyme. Biotechnol Biofuels. 2014;7(1):163 (PubMed PMID: 25431621. Pubmed Central PMCID: 4245778)

16. Arai T, Kuwahara S. Studies on the influence of minute amounts of fatty acids in bacteriological culture media on bacterial growth (I). Growthaccelerating action of trace amounts of fatty acids in vitamin-free casin acid-hydrolysate on Streptococcus hemolyticus strain S-8. Japanese. J Microbiol. 1961;5:327-35.

17. Annous BA, Blaschek HP. Isolation and characterization of Clostridium acetobutylicum mutants with enhanced amylolytic activity. Appl Environ Microbiol. 1991;57(9):2544-8 (PubMed PMID: 1722664. Pubmed Central PMCID: 183617).

18. Tracy BP, Jones SW, Papoutsakis ET. Inactivation of sigma(E) and sigma(G) in Clostridium acetobutylicum illuminates their roles in clostridial-cellform biogenesis, granulose synthesis, solventogenesis, and spore morphogenesis. J Bacteriol. 2011;193(6):1414-26 (PubMed PMID: WOS:000287696100015. English).

19. Rappert S, Song L, Sabra W, Wang W, Zeng AP. Draft genome sequence of type strain Clostridium pasteurianum DSM 525 (ATCC 6013), a promising producer of chemicals and fuels. Genome Announc. 2013;1(1) (PubMed PMID: 23469350. Pubmed Central PMCID: 3587944).

20. Rotta C, Poehlein A, Schwarz K, McClure P, Daniel R, Minton NP. Closed genome sequence of Clostridium pasteurianum ATCC 6013. Genome Announc. 2015;3(1) (PubMed PMID: 25700419. Pubmed Central PMCID: 4335343).

21. Poehlein A, Grosse-Honebrink A, Zhang Y, Minton NP, Daniel R. Complete genome sequence of the nitrogen-fixing and solvent-producing Clostridium pasteurianum DSM 525. Genome Announc. 2015;3(1) (PubMed PMID: 25700415. Pubmed Central PMCID: 4335339).

22. Harris LM, Welker NE, Papoutsakis ET. Northern, morphological, and fermentation analysis of spo0A inactivation and overexpression in Clostridium acetobutylicum ATCC 824. J Bacteriol. 2002;184(13):3586-97 (PubMed PMID: 12057953. Pubmed Central PMCID: 135115).

23. Kormanec J, Potuckova L, Rezuchova B. The Streptomyces aureofaciens homologue of the whiG gene encoding a putative sigma factor essential for sporulation. Gene. 1994;143(1):101-3.

24. Li F, Hinderberger J, Seedorf H, Zhang J, Buckel W, Thauer RK. Coupled ferredoxin and crotonyl coenzyme A (CoA) reduction with NADH catalyzed by the butyryl-CoA dehydrogenase/Etf complex from Clostridium kluyveri. J Bacteriol. 2008;190(3):843-50 (PubMed PMID: 17993531. Pubmed Central PMCID: 2223550)

25. Lewis RJ, Krzywda S, Brannigan JA, Turkenburg JP, Muchova K, Dodson EJ, et al. The trans-activation domain of the sporulation response regulator Spo0A revealed by X-ray crystallography. Mol Microbiol. 2000;38(2):198-212.

26. Ravagnani A, Jennert KC, Steiner E, Grunberg R, Jefferies JR, Wilkinson SR, et al. Spo0A directly controls the switch from acid to solvent production in solvent-forming clostridia. Mol Microbiol. 2000;37(5):1172-85.

27. Patakova P, Linhova M, Rychtera M, Paulova L, Melzoch K. Novel and neglected issues of acetone-butanol-ethanol (ABE) fermentation by clostridia: Clostridium metabolic diversity, tools for process mapping and continuous fermentation systems. Biotechnol Adv. 2013;31(1):58-67 (PubMed PMID: 22306328) 
28. Nair RV, Bennett GN, Papoutsakis ET. Molecular characterization of an aldehyde/alcohol dehydrogenase gene from Clostridium-acetobutylicum ATCC-824. J Bacteriol. 1994;176(3):871-85 (PubMed PMID: WOS:A1994MU15100037).

29. Nair RV, Papoutsakis ET. expression of plasmid-encoded AAD in Clostridium-acetobutylicum M5 restores vigorous butanol production. J Bacteriol. 1994;176(18):5843-6 (PubMed PMID: WOS:A1994PF22200031).

30. Wiesenborn DP, Rudolph FB, Papoutsakis ET. Coenzyme-A transferase from clostridium-acetobutylicum ATCC-824 and its role in the uptake of acids. Appl Environ Microbiol. 1989;55(2):323-9 (PubMed PMID: WOS:A1989T150000011)

31. Papoutsakis ET. Engineering solventogenic clostridia. Curr Opin Biotechnol. 2008;19(5):420-9 (PubMed PMID: WOS:000260387900003)

32. Cornillot E, Nair RV, Papoutsakis ET, Soucaille P. The genes for butanol and acetone formation in Clostridium acetobutylicum ATCC 824 reside on a large plasmid whose loss leads to degeneration of the strain. J Bacteriol. 1997;179(17):5442-7 (PubMed PMID: WOS:A 1997XT77200027).

33. Fontaine L, Meynial-Salles I, Girbal L, Yang XH, Croux C, Soucaille P. Molecular characterization and transcriptional analysis of adhE2, the gene encoding the NADH-dependent aldehyde/alcohol dehydrogenase responsible for butanol production in alcohologenic cultures of Clostridium acetobutylicum ATCC 824. J Bacteriol. 2002;184(3):821-30 (PubMed PMID: WOS:000173364000025).

34. Thormann K, Feustel L, Lorenz K, Nakotte S, Durre P. Control of butanol formation in Clostridium acetobutylicum by transcriptional activation. J Bacteriol. 2002;184(7):1966-73 (PubMed PMID: 11889105. Pubmed Central PMCID: 134926)

35. Wang Y, Li X, Mao Y, Blaschek HP. Single-nucleotide resolution analysis of the transcriptome structure of Clostridium beijerinckii NCIMB 8052 using RNA-Seq. BMC Genom. 2011;12:479 (PubMed PMID: 21962126. Pubmed Central PMCID: 3271303)

36. Al-Hinai MA, Jones SW, Papoutsakis ET. The Clostridium sporulation programs: diversity and preservation of endospore differentiation. Microbiol Mol Biol Rev. 2015;79(1):19-37 (PubMed PMID: WOS:000350978300002)

37. Jones SW, Tracy BP, Gaida SM, Papoutsakis ET. Inactivation of sigma(F) in Clostridium acetobutylicum ATCC 824 blocks sporulation prior to asymmetric division and abolishes sigma(E) and sigma(G) protein expression but does not block solvent formation. J Bacteriol. 2011;193(10):2429-40 (PubMed PMID: WOS:000289983100006).

38. Al-Hinai MA, Jones SW, Papoutsakis ET. Sigma(K) of Clostridium acetobutylicum is the first known sporulation-specific sigma factor with two developmentally separated roles, one early and one late in sporulation. J Bacteriol. 2014;196(2):287-99 (PubMed PMID: WOS:000332624300009)

39. Clark TA, Lu X, Luong K, Dai Q, Boitano M, Turner SW, et al. Enhanced 5-methylcytosine detection in single-molecule, real-time sequencing via Tet1 oxidation. BMC Biol. 2013;11:4 (PubMed PMID: 23339471. Pubmed Central PMCID: 3598637$)$

40. Richards DF, Linnett PE, Oultram JD, Young M. Restriction endonucleases in Clostridium pasteurianum ATCC 6013 and C. thermohydrosulfuricum DSM 568. J Gen Microbiol. 1988;134(12):3151-7.
41. Al-Hinai MA, Fast AG, Papoutsakis ET. Novel system for efficient isolation of Clostridium double-crossover allelic exchange mutants enabling markerless chromosomal gene deletions and DNA integration. Appl Environ Microbiol. 2012;78(22):8112-21 (PubMed PMID: 22983967. Pubmed Central PMCID: 3485963. Epub 2012/09/18. eng).

42. Jones SW, Paredes CJ, Tracy B, Cheng N, Sillers R, Senger RS, et al. The transcriptional program underlying the physiology of clostridial sporulation. Genome Biol. 2008;9(7):R114 (PubMed PMID: 18631379. Pubmed Central PMCID: 2530871)

43. Ebersold HR, Cordier JL, Luthy P. Bacterial mesosomes: method dependent artifacts. Arch Microbiol. 1981;130(1):19-22.

44. Paredes CJ, Alsaker KV, Papoutsakis ET. A comparative genomic view of clostridial sporulation and physiology. Nat Rev Microbiol. 2005;3(12):96978 (PubMed PMID: WOS:000233668900016).

45. Steiner E, Dago AE, Young DI, Heap JT, Minton NP, Hoch JA, et al. Multiple orphan histidine kinases interact directly with Spo0A to control the initiation of endospore formation in Clostridium acetobutylicum. Mol Microbiol. 2011;80(3):641-54 (PubMed PMID: 21401736. Pubmed Central PMCID: 3097173)

46. Xu M, Zhao J, Yu L, Tang IC, Xue C, Yang ST. Engineering Clostridium acetobutylicum with a histidine kinase knockout for enhanced n-butanol tolerance and production. Appl Microbiol Biotechnol. 2015;99(2):1011-22.

47. Alsaker KV, Spitzer TR, Papoutsakis ET. Transcriptional analysis of spo0A overexpression in Clostridium acetobutylicum and its effect on the cell's response to butanol stress. J Bacteriol. 2004;186(7):1959-71 (PubMed PMID:WOS:000220363200006)

48. Husemann MHW, Papoutsakis ET. Solventogenesis in Clostridiumacetobutylicum fermentations related to carboxylic-acid and proton concentrations. Biotechnol Bioeng. 1988;32(7):843-52 (PubMed PMID: WOS:A1988P977800001)

49. Zhao YS, Tomas CA, Rudolph FB, Papoutsakis ET, Bennett GN. Intracellular butyryl phosphate and acetyl phosphate concentrations in Clostridium acetobutylicum and their implications for solvent formation. Appl Environ Microbiol. 2005;71(1):530-7 (PubMed PMID: WOS:000226458800066)

50. Meyer CL, Roos JW, Papoutsakis ET. Carbon-monoxide gasing leads to alcohol production and butyrate uptake without acetone formation in continuous cultures of Clostridium-acetobutylicum. Appl Microbiol Biotechnol. 1986;24(2):159-67 (PubMed PMID: WOS:A1986C537600013)

51. Tracy BP, Jones SW, Fast AG, Indurthi DC, Papoutsakis ET. Clostridia: the importance of their exceptional substrate and metabolite diversity for biofuel and biorefinery applications. Curr Opin Biotechnol. 2012;23(3):364-81 (PubMed PMID: WOS:000305862100011).

52. Oultram JD, Loughlin M, Swinfield TJ, Brehm JK, Thompson DE, Minton NP. Introduction of plasmids into whole cells of Clostridium-Acetobutylicum by electroporation. FEMS Microbiol Lett. 1988;56(1):83-8 (PubMed PMID: WOS:A 1988R332300014. English)

Submit your next manuscript to BioMed Central and we will help you at every step:

- We accept pre-submission inquiries

- Our selector tool helps you to find the most relevant journal

- We provide round the clock customer support

- Convenient online submission

- Thorough peer review

- Inclusion in PubMed and all major indexing services

- Maximum visibility for your research

Submit your manuscript at www.biomedcentral.com/submit

C BioMed Central 